\title{
Fábrica do Paleão: Structural Assessment of Iron in Portugal's Industrial Heritage
}

KRICHKO Kori ${ }^{1, a}$, VALENTE Isabel B..$^{2^{*}, b}$

1'kori.krichko@gmail.com; ${ }^{2 * i s a b e l v @ c i v i l . u m i n h o . p t ~(c o r r e s p o n d i n g ~ a u t h o r) ~}$

a Structural EIT at Meyer Borgman Johnson and Former student of the SAHC Program - Erasmus Mundus Advanced Masters in Structural Analysis of Monuments and Historical Constructions ' ISISE - Institute for Sustainability and Innovation in Structural Engineering University of Minho, School of Engineering, Department of Civil Engineering Campus de Azurém, 4800-058 Guimarães, Portugal.

Tel: +351253510 203; Fax: +351253510217

\section{ABSTRACT}

Fábrica do Paleão was erected as a flagship textile factory in Portugal between 1888 and 1891. The factory was constructed with a saw-tooth roof supported by iron trusses allowing light open spaces to accommodate heavy machinery and promote industrial activity.

With an aim of preserving this exemplary representative of industrial heritage in Portugal, the work seeks to establish the buildings' historical significance and assess their structural adequacy for present and future use.

After performing a global historical survey and visual inspection, the study focused on the main industrial spaces. An in depth visual inspection provided key geometric and material parameters as well as a damage assessment. Damage mapping revealed the effects of moisture throughout the structure which is caused by the lack of maintenance in recent years.

To assess the impact of the damages and obtain key parameters for a further structural and safety analysis, in situ tests were performed on the cast iron columns. Columns were tested for hardness and comparison to known values indicate that they align with ordinary to high strength cast iron. A representative single frame was modelled for each of the two main rooms and a safety analysis was performed to assess the structure's safety.

Krichko, Kori; Valente, Isabel B. (2018)

Fábrica do Paleão: Structural Assessment of Iron in Portugal's Industrial Heritage.

Paper submitted to Proceedings of the Institution of Civil Engineers -

Engineering History and Heritage, ISSN 1757-9430. 


\section{Keywords}

Buildings, Steel structures, Conservation, Field testing \& monitoring, Safety.

Krichko, Kori; Valente, Isabel B. (2018)

Fábrica do Paleão: Structural Assessment of Iron in Portugal's Industrial Heritage.

Paper submitted to Proceedings of the Institution of Civil Engineers -

Engineering History and Heritage, ISSN 1757-9430. 


\section{INTRODUCTION}

A number of inventions, developments and a "laissez faire" economy are credited for spurring the Industrial Revolution that began in England in the late $18^{\text {th }}$ century. This time marked the beginning of a period of technological advances and rapid industrial growth, changing the way people lived and thought. Some of the most notable advances were the factory system, steam powered machines, iron production and improved transportation systems. The interconnectedness of these developments furthered and spread the industrial movement. One such interdependent relationship was the factory system and iron production. The revolution demanded the rapid construction of a number of large buildings to house heavy vibratory machinery and factory workers. Coal and the factory system made a cheaper, stronger iron available for this purpose. As a result, factories housing advanced equipment supported by innovative materials of the age were constructed around the world. Those that remain today should be preserved as important reminders of our industrial heritage.

As part of this "industrial archaeology", Fábrica do Paleão is an early example of a factory in Portugal utilizing iron and steel as a structural material

\subsection{Description of the buildings and summary of the work developed}

Following the vision of a prominent local lawyer, Evaristo F. Carvalho, Fábrica do Paleão was erected between 1888 and 1891 in the agricultural region of Soure, located within the Coimbra district. Designed according to the latest industrial building technology from England and France, the textile plant was able to profit from the abundant waters of the region, a nearby coal deposit and the low wages of farm workers to rival larger plants in Lisbon and Porto. Due to the profitable economic conditions of the region, advanced structural design for the period and several effective administrations, the factory remained active for over 100 years, surviving many political and economic crises in Portugal until finally closing in 1994. During its operation, the factory was the centre of economic and cultural activity in the region, encouraging locals to work, live and engage in social activities organized by the administration. Since closing its doors, the surrounding land has returned to its agricultural roots, leaving the structure abandoned for over two decades.

Krichko, Kori; Valente, Isabel B. (2018)

Fábrica do Paleão: Structural Assessment of Iron in Portugal's Industrial Heritage.

Paper submitted to Proceedings of the Institution of Civil Engineers -

Engineering History and Heritage, ISSN 1757-9430. 
Implementing the latest industrial design, the factory was constructed with a saw-tooth roof supported by an internal iron structure allowing light open spaces to accommodate heavy machinery and promote industrial activity.

After performing a global historical survey and initial visual inspection, the study became focused on the main industrial spaces, namely the spinning and weaving sections. These rooms exploit the expansive naturally lit spaces created by the internal metallic structure from the original design. A more in depth visual inspection provided key geometric and material parameters and an initial damage assessment.

To assess the impact of the moisture damages and obtain key parameters for a further structural and safety analysis, in situ tests were performed on the cast iron columns. With the results of these tests and other parameters gathered in the visual inspection, a single frame, representative of the series of frames constituting the internal structure, was modelled for each of the two main rooms. The models were analysed for two loads cases, accounting for the presence or absence of wind to perform a safety analysis on the present structure and assess its suitability for new uses.

\section{$1.2 \quad$ Research aims and objectives}

This paper aims to assess the present state of Fábrica do Paleão encouraging its preservation to ensure the longevity of this prime example of industrial heritage in Portugal. To achieve this, the following specific objectives are named:

- Emphasize the historical significance of Fábrica do Paleão for Portugal's industrial heritage.

- Document the present state and main damages in the factory.

- Perform necessary in situ tests to determine the extent of observed damages.

- Complete a structural analysis and to assess the adequacy of the structure for present or future uses.

Krichko, Kori; Valente, Isabel B. (2018)

Fábrica do Paleão: Structural Assessment of Iron in Portugal's Industrial Heritage.

Paper submitted to Proceedings of the Institution of Civil Engineers -

Engineering History and Heritage, ISSN 1757-9430. 


\section{HISTORICAL SURVEY}

\subsection{Industrial plant conception}

Paleão was a small independent village until it came under the jurisdiction of the Soure municipality in 1694. The agricultural community with rural traditions benefitted from the natural landscape of flat fields and abundant waters trapped by surrounding mountains. However, the industrial potential of the region was not realized until it was recognized by Evaristo Ferreira de Carvalho, who was raised in the region. In 1884, this prominent lawyer hired Scipião Bouvret to complete a hydraulic study to justify the construction of a large industrial plant to investors and local inhabitants. It was decided that the plant area was to be placed next to the river, after the junction of the Orão and Anços rivers, profiting from a strong hydraulic force (Custódio, 1998).

Beyond the powerful waters of the Anços and Orão rivers, the land benefitted from easy accessibility, abundant natural resources and an advantageous local economy. Located at a river link to Figueira da Foz, on a railway stop and with municipal roads passing through, the proposed site was at the center of communication. Additionally, the rural location provided healthy land, light and air for a factory with access to nearby lignite deposits and Buarcos coal to fuel steam engines. The final advantage recognized by Carvalho was the low wages of the agricultural workers of the area. Without intending to exploit the workers, a factory in the Soure region could offer lower wages (Custódio, 1998).

After considering alternative industries, Evaristo Carvalho and a number of other shareholders, agreed to implement a new cotton plant on the site. While there was substantial national and international competition for cotton textiles, the national demand for cotton was enough to justify the investment. To ensure the success of the plant, the factory was to be constructed to match innovative foreign models, implementing the latest designs and available technology.

\subsection{Evolution of the Structure}

To guarantee its success, the factory was built according to the latest most innovative foreign models. Contractor, Francisco Baerlein, and French engineer, Scipião Bouvret, were hired to develop and construct a plan for the factory considering efficient labor practices, architectural design and social concerns. The complete plan of the working factory from 1911 has been

Krichko, Kori; Valente, Isabel B. (2018)

Fábrica do Paleão: Structural Assessment of Iron in Portugal's Industrial Heritage.

Paper submitted to Proceedings of the Institution of Civil Engineers -

Engineering History and Heritage, ISSN 1757-9430. 
provided in Figure 1.a to show the resulting design. It should be noted that the original construction was completed 20 years earlier, in 1891, with some slight alterations discussed in the following section.

To create an efficient labor space, all of the operations of the plant are included in one plant area. Spinning and weaving, the two main sections, occupy the largest areas with spinning initially designed to be larger. A number of smaller rooms, including various workshops and rooms housing the energy systems, are adjacent these large industrial spaces. The layout is designed in a way so that the supporting workshops flank the main operative spaces, which are divided by a central corridor. While each of the rooms is dedicated to a separate function, the operations are dependent on each other with the two main spaces working together, imposing the pace of production at the plant.

Developed after the construction of the factory, the social considerations completed the design of the factory. A number of landscaped spaces and gardens for small agricultural activity were created on the grounds to link the plant to its agricultural surroundings and allow and yet control the workers' leisure activities. To fully establish the patriarchal factory, two large homes for the administrator and director were constructed next to the working-class neighborhood to support the administrators' governance over the factory and the village. To complete the social design, a primary school was included in the main factory with socio-cultural spaces added in later years.

\subsection{Structural Design}

A saw-tooth roof configuration was created by constructing series of dual-pitched ridges with one steep and one gradual slope in order to create light open spaces to promote efficient industrial activity at the plant. Glass panels were applied to the steep grade oriented to the North, allowing natural light to fill the interior space. Thin wrought iron trusses supported the saw-tooth roof without blocking light from entering the large open spaces. These large spaces accommodate heavy machinery and adequate natural light to promote productivity were essential design criteria to create efficient industrial activity at the plant. To meet these criteria a light metallic framed structure was designed to create an open floor plan. The internal structure was composed of a series roof trusses supported by iron columns beneath the junction of each bay in the roof system. While the frame configuration of the two main rooms is the same, the scale of the rooms differs

Krichko, Kori; Valente, Isabel B. (2018)

Fábrica do Paleão: Structural Assessment of Iron in Portugal's Industrial Heritage.

Paper submitted to Proceedings of the Institution of Civil Engineers -

Engineering History and Heritage, ISSN 1757-9430. 
due to the machinery and workspaces required by each industrial activity. In the weaving section, referred to as room A, larger spaces were necessary. Therefore, the span of the trusses and distance between the frames is greater than the frames in the spinning section, or room B. The larger spaces in room A necessitated more robust trusses with greater sections supporting larger roof areas. The rooms were enclosed in heavy masonry walls. Intended to be load-bearing, the wall section was increased where the roof trusses meet the wall.

The photographs in Figure 1.b and Figure 1.c of the main operational rooms in 1900 demonstrate the type of machinery and natural light that filled the spaces due to the structural design of the plant.

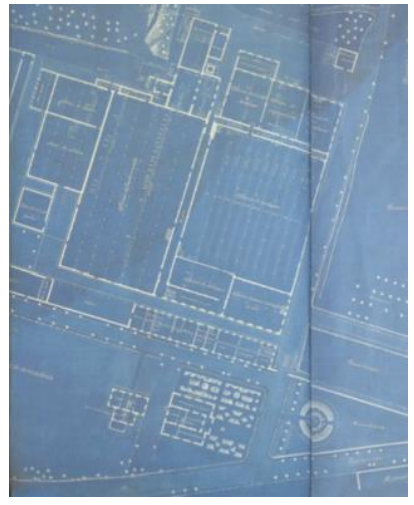

(a) Plan of the factory

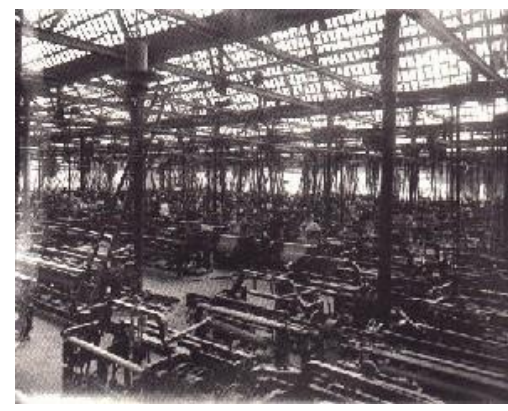

(b) The weaving section

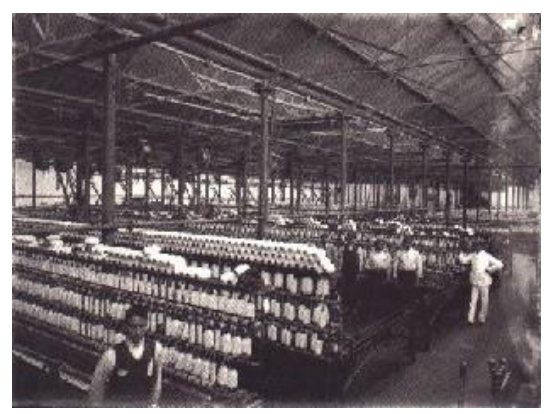

(c) The spinning section

Figure 1 - Plan of the factory (1911) and main operational spaces (1900) (Custódio, 1998)

A number of project plans indicate the post-construction modifications that were completed at the factory during its 103 years in operation. These alterations tend to align with the various administrations, as each new owner demanded the installation of the latest technology. The majority of the renovations focused on electrical and mechanical upgrades with minor structural modifications.

Photographs obtained during the inspection survey have been organized (Error! Reference source not found.). The display affirms the historic integrity of the existing structure, with few major alterations since the erection of the factory. However, the figures presented also highlight the result of 20 years of vacancy and lack of maintenance since closing its doors in 1994.

Krichko, Kori; Valente, Isabel B. (2018)

Engineering History and Heritage, ISSN 1757-9430. 


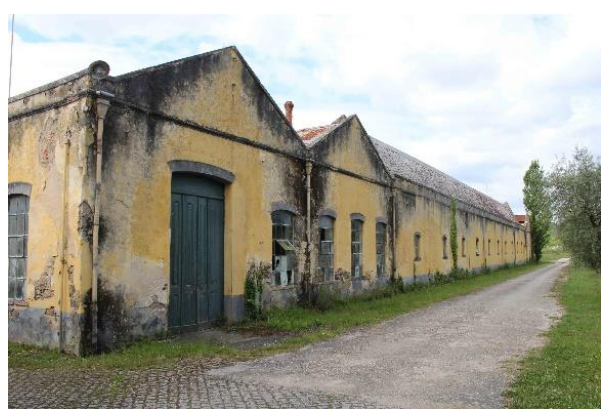

a) General exterior view

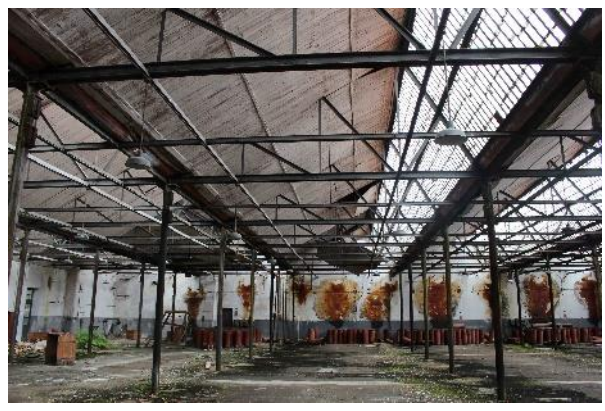

c) Room A (weaving section)

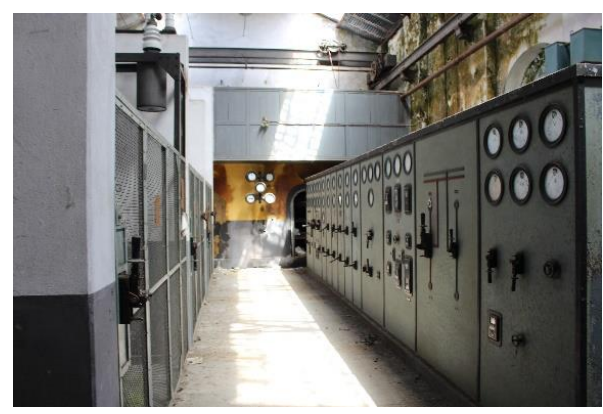

e) Central electric unit

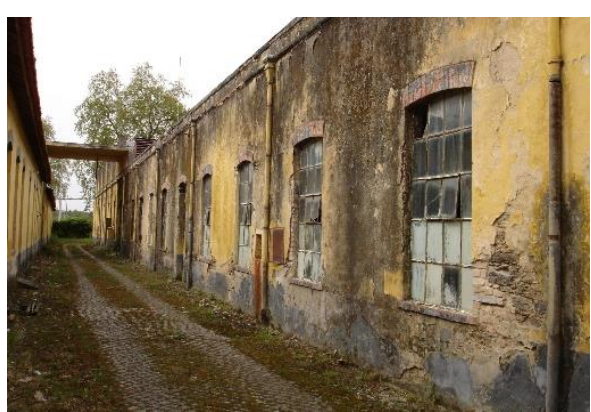

b) Lateral exterior view

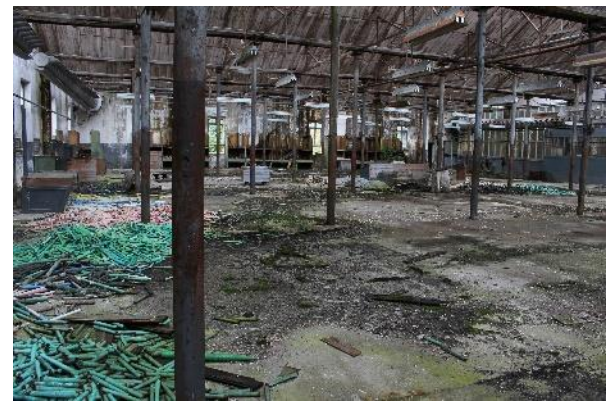

d) Room B (spinning section)

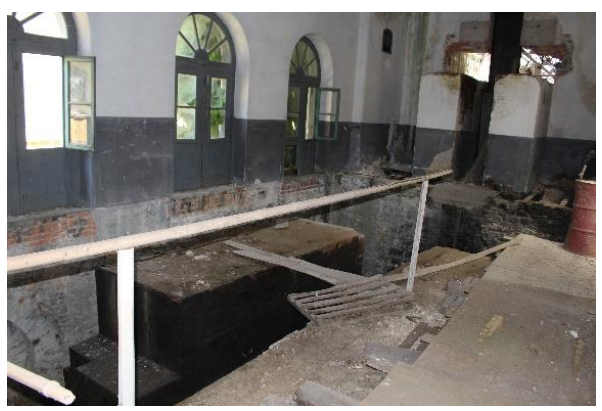

f) Former location of the steam engine designed by Buckley \& Taylor Engineers from Oldham, in 1898

Figure 2 - Overview on the factory's main spaces

\section{SITE SURVEY}

A visual inspection was performed with a camera, a few simple measuring tools and former plans to determine the structure's geometry, material composition and damages for further structural evaluation. Results of this survey are summarized in the following sections.

Krichko, Kori; Valente, Isabel B. (2018)

Fábrica do Paleão: Structural Assessment of Iron in Portugal's Industrial Heritage.

Paper submitted to Proceedings of the Institution of Civil Engineers -

Engineering History and Heritage, ISSN 1757-9430. 


\section{1}

Geometric and material survey

A current plan of the structure was generated with architectural drawings from 1949, the latest available, and verified with on-site measurements. This plan with one section view crossing the two largest workshops of the factory is displayed in this section.

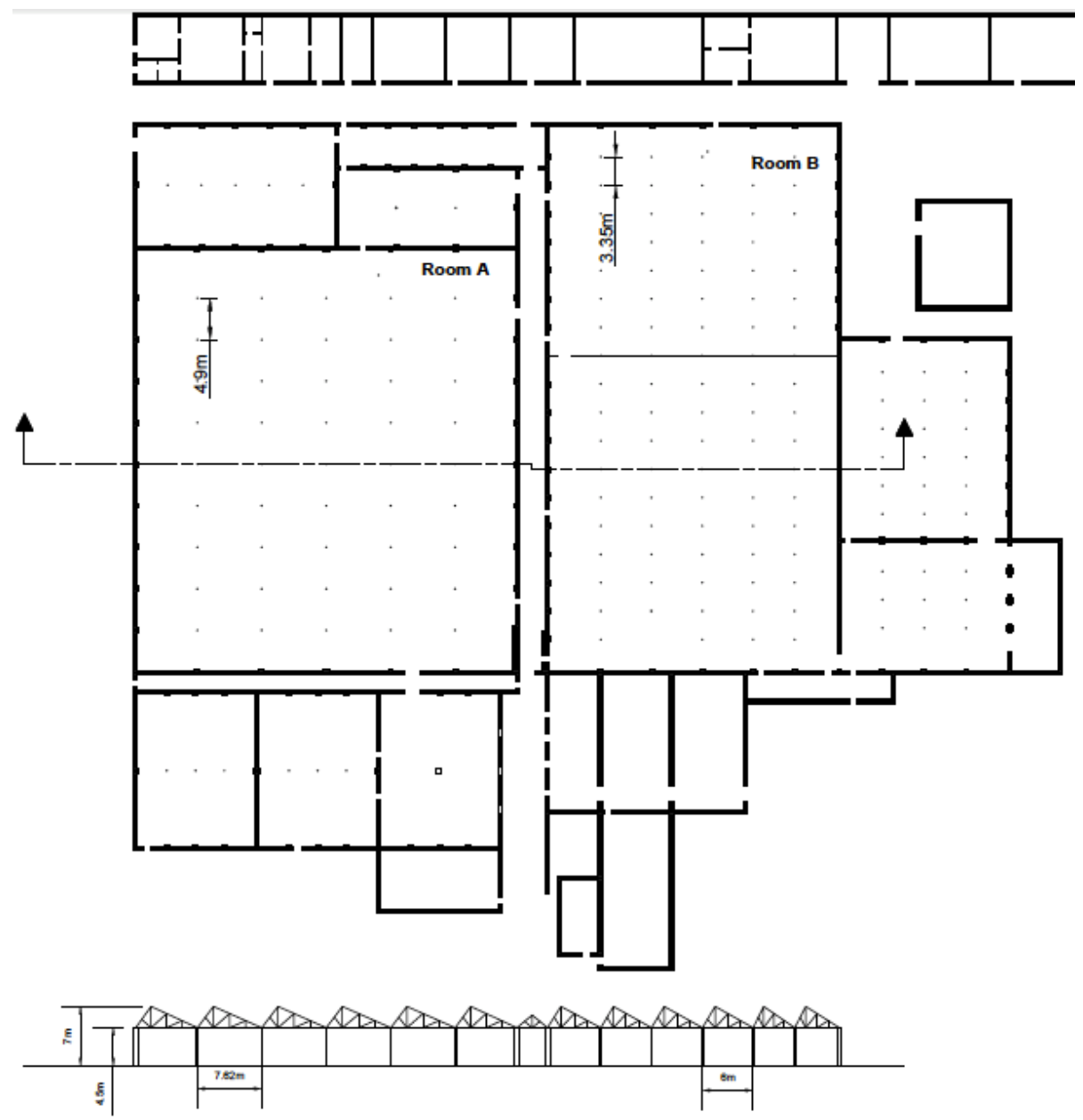

Figure 3 - Plan and section view and demarcation of the main industrial spaces

\section{Masonry Walls}

A number of measurements were taken of the interior and exterior walls. With the exception of narrow partition walls and thicker sections, marked in the plan, the majority of the walls are $42 \mathrm{~cm}$ wide with thicker sections supporting the roof trusses. An overall view of the design can be viewed in the plan of the factory, with the specific geometric configuration displayed in Figure 4.a.

Krichko, Kori; Valente, Isabel B. (2018)

Fábrica do Paleão: Structural Assessment of Iron in Portugal's Industrial Heritage.

Paper submitted to Proceedings of the Institution of Civil Engineers -

Engineering History and Heritage, ISSN 1757-9430. 


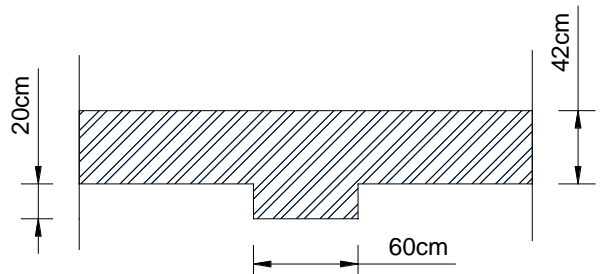

a) wall section dimensions

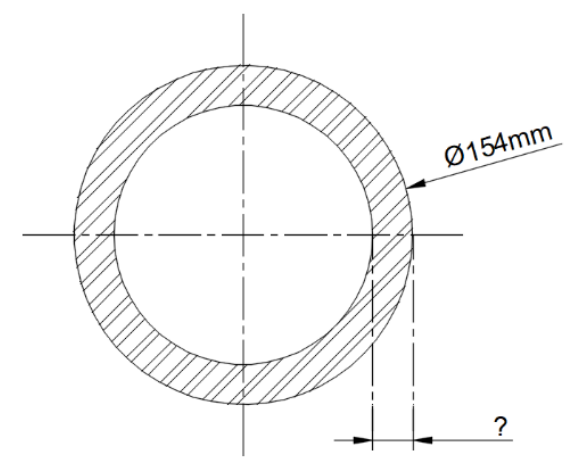

b) hollow circular column cross-section with incomplete dimensions

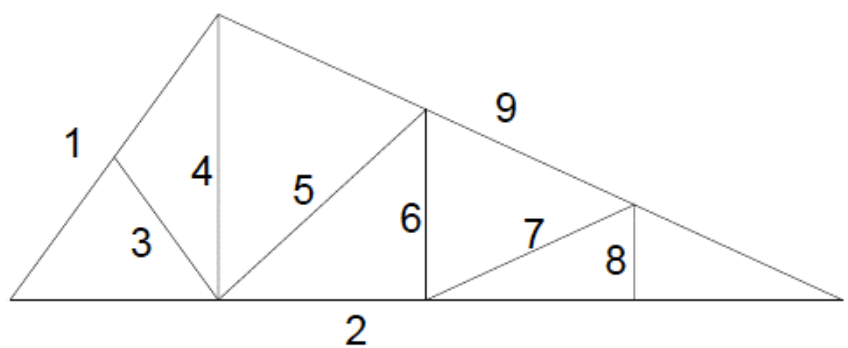

c) Roof truss configuration and member identification

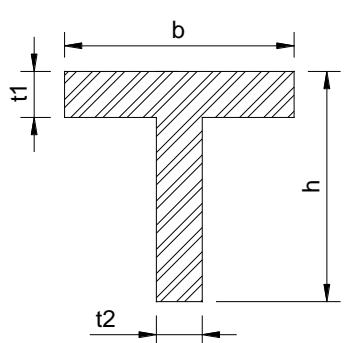

d) Roof truss: T-bar in compression members (elements 1, 3, 5, 7, 9)

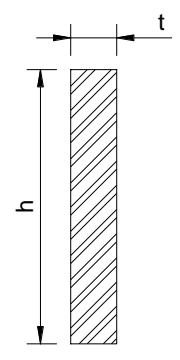

e) Roof truss: Flat $\quad$ f) Roof truss: double C-section members bars in tension members

(elements 2, 4, 6,

8)

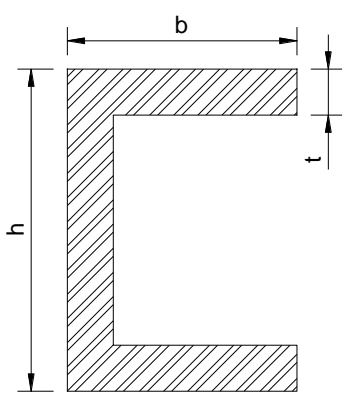

in tension for large spans (element 2 in Room A)

Figure 4 - Truss element dimensions

\section{Interior Columns}

While already suspected due to the common column sections utilized at the time of construction (Bates, 1991), knocking on the columns with a hard object confirmed that the round columns are hollow. The outer diameter of the member could be measured, but it was not possible to determine the wall thickness or interior diameter during the visual inspection. The proposed section and measured exterior diameter is given in Figure 4.b.

Krichko, Kori; Valente, Isabel B. (2018)

Fábrica do Paleão: Structural Assessment of Iron in Portugal's Industrial Heritage.

Paper submitted to Proceedings of the Institution of Civil Engineers -

Engineering History and Heritage, ISSN 1757-9430. 


\section{Truss Elements}

The roof truss configuration displayed in Figure 4.c is valid for both of the main rooms in the factory. Dimensions are not included, as the measurements vary by the total length of the truss, with longer spans and thicker dimensions for the larger trusses. However, the configuration has been labeled to identify the members measured.

The three member sections identified in the trusses are T-bars, flat bars and double C-section members. Each section has been illustrated with dimensions labeled for measurement identification. With the exception of double C-section for member 2 of the larger trusses in Room A, all of the compression members are T-bar and flat bars utilized in tension. Complete member identification and measurements are included in Table 1.

Table 1 - Values for the trusses measured in Room A and Room B

\begin{tabular}{|c|c|c|c|c|c|c|c|}
\hline \multicolumn{4}{|c|}{$\begin{array}{c}\text { ROOM A } \\
\text { Total length }=7.62 \mathrm{~m}\end{array}$} & \multicolumn{4}{|c|}{$\begin{array}{c}\text { ROOM B } \\
\text { Total length }=6.00 \mathrm{~m}\end{array}$} \\
\hline Member & $\begin{array}{l}\text { Cross } \\
\text { section }\end{array}$ & $\begin{array}{c}\text { Dimension } \\
\text { notation }\end{array}$ & $\begin{array}{c}\text { Average } \\
\text { measurement } \\
(\mathrm{mm})\end{array}$ & Member & $\begin{array}{l}\text { Cross } \\
\text { section }\end{array}$ & $\begin{array}{c}\text { Dimension } \\
\text { notation }\end{array}$ & $\begin{array}{c}\text { Average } \\
\text { measurement } \\
(\mathrm{mm})\end{array}$ \\
\hline \multirow[t]{4}{*}{1} & \multirow[t]{4}{*}{ T-bar } & $h$ & 103.03 & \multirow[t]{4}{*}{1} & \multirow[t]{4}{*}{ T- bar } & $h$ & 76.57 \\
\hline & & $t_{1}$ & 10.36 & & & $t_{1}$ & 9.75 \\
\hline & & $b$ & $101.77^{*}$ & & & $b$ & 72.15 \\
\hline & & $t_{2}$ & 9.03 & & & $t_{2}$ & 8.07 \\
\hline \multirow[t]{4}{*}{2} & \multirow{4}{*}{$\begin{array}{l}\text { Double } \\
\text { Channel }\end{array}$} & $h$ & 147.52 & \multirow[t]{2}{*}{2} & \multirow[t]{2}{*}{ Flat bar } & $h$ & 63.57 \\
\hline & & $b$ & 59.69 & & & $t$ & 10.94 \\
\hline & & $t$ & 11.63 & & & & \\
\hline & & Spacing & 31.37 & & & & \\
\hline \multirow[t]{4}{*}{3} & \multirow[t]{4}{*}{ T-bar } & $h$ & 77.85 & \multirow[t]{4}{*}{3} & \multirow[t]{4}{*}{ T-bar } & $h$ & 62.99 \\
\hline & & $t_{1}$ & 10.91 & & & $t_{1}$ & 9.67 \\
\hline & & $b$ & 77.71 & & & $b$ & 62.84 \\
\hline & & $t_{2}$ & 9.62 & & & $t_{2}$ & 7.98 \\
\hline \multirow[t]{2}{*}{4} & \multirow[t]{2}{*}{ Flat bar } & $h$ & 49.81 & \multirow[t]{2}{*}{4} & \multirow[t]{2}{*}{ Flat bar } & $h$ & 50.45 \\
\hline & & $t$ & 10.11 & & & $t$ & 8.46 \\
\hline \multirow[t]{4}{*}{5} & \multirow[t]{4}{*}{ T-bar } & $h$ & 77.61 & \multirow[t]{4}{*}{5} & \multirow[t]{4}{*}{ T-bar } & $h$ & 63.71 \\
\hline & & $t_{1}$ & 10.26 & & & $t_{1}$ & 8.29 \\
\hline & & $b$ & 76.92 & & & $b$ & 62.88 \\
\hline & & $t_{2}$ & 9.28 & & & $t_{2}$ & 7.87 \\
\hline \multirow[t]{2}{*}{6} & \multirow[t]{2}{*}{ Flat bar } & $h$ & 50.04 & \multirow[t]{2}{*}{6} & \multirow[t]{2}{*}{ Flat bar } & $h$ & 38.32 \\
\hline & & $t$ & 10.04 & & & $t$ & 6.12 \\
\hline \multirow[t]{4}{*}{7} & \multirow[t]{4}{*}{ T-bar } & $h$ & 77.06 & \multirow[t]{4}{*}{7} & T-bar & $h$ & 51.09 \\
\hline & & $t_{1}$ & 10.23 & & & $t_{1}$ & 8.38 \\
\hline & & $b$ & 76.66 & & & $b$ & 50.69 \\
\hline & & $t_{2}$ & 9.42 & & & $t_{2}$ & 6.75 \\
\hline 8 & Flat bar & $h$ & 49.36 & 8 & Flat bar & $h$ & 38.38 \\
\hline & & $t$ & 10.10 & & & $t$ & 6.19 \\
\hline 9 & T-bar & $h$ & 105.38 & 9 & T-bar & $h$ & $76.57^{\star *}$ \\
\hline & & $t_{1}$ & 10.11 & & & $t_{1}$ & $9.75^{\star *}$ \\
\hline & & $b$ & 101.77 & & & $b$ & $72.15^{\star \star *}$ \\
\hline & & $t_{2}$ & 10.40 & & & $t_{2}$ & $8.07^{\star *}$ \\
\hline
\end{tabular}

Krichko, Kori; Valente, Isabel B. (2018)

Fábrica do Paleão: Structural Assessment of Iron in Portugal's Industrial Heritage.

Paper submitted to Proceedings of the Institution of Civil Engineers -

Engineering History and Heritage, ISSN 1757-9430. 
*Dimension not accessible for direct measurement so value taken as the height of member 9 , which was found to have similar dimensions.

${ }^{* *}$ Member 9 was not accessible for direct measurement, so values are assumed to be the same as member 9 based on the pattern observed for the truss measured in room $A$.

\subsection{Material Identification}

Before performing any type of structural assessment, the material properties and dimensions must be determined. This section identifies and justifies the material properties and dimensions utilized in the structural analysis.

It should be noted that sampling would have been useful to distinguish between wrought iron and steel, but no metallic structural elements were available for laboratory testing. Consequently, other methods were engaged to estimate the material with certain assumptions justified and discussed.

\section{Exterior walls}

The exterior walls are finished with a layer of mortar applied as an aesthetic sacrificial layer. Spalling present in various locations exposes the rubble masonry beneath. The thick walls appear to be composed of stones varying in size and shape. The loss of the sacrificial layers also reveals timber inclusions within the walls.

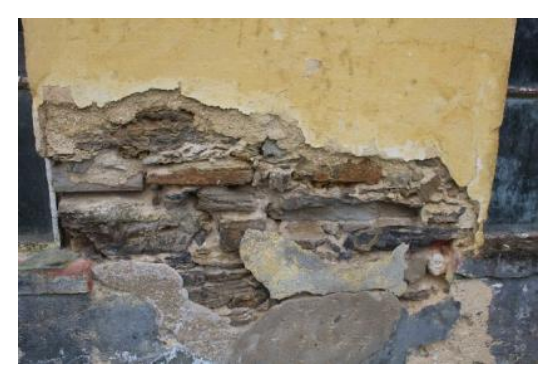

a) Rubble masonry

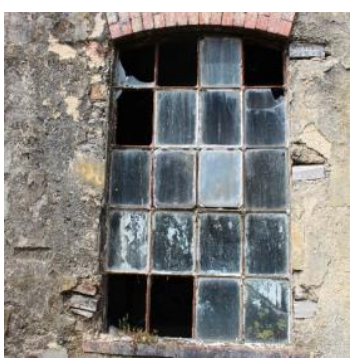

b) Timber inclusions concentrated around the window openings

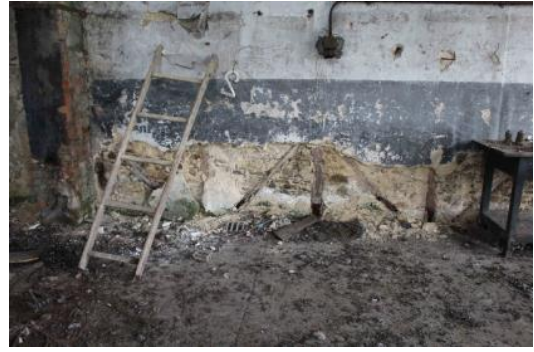

c) Diagonal bracing within a masonry wall

Figure 5 - Damages in exterior and interior walls have exposed (a) Rubble masonry, (b) Timber inclusions concentrated around the window openings, (c) Diagonal bracing within a masonry wall

Krichko, Kori; Valente, Isabel B. (2018)

Engineering History and Heritage, ISSN 1757-9430. 
All of the interior walls are finished with a smooth plaster and layer of paint, making it difficult to visually assess the wall morphology. In some cases, the wall composition can be determined by assuming continuity to the exterior walls due to matching wall sections. It is also known that masonry interior partition walls were constructed to provide fire resistance and increase the load bearing capacity. These measures were taken prior to a full understanding of the strength of metallic structural elements.

\section{Columns}

The metal in the columns was easily identified by visual inspection, application and confirmed by the date of erection. Photographic evidence has been provided to illustrate the identifying features in Figure 6.

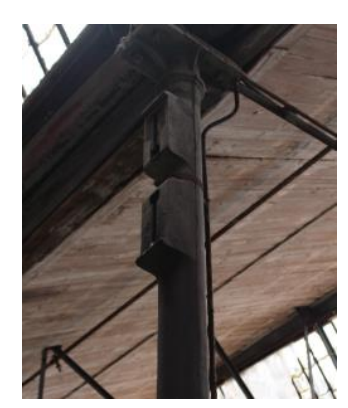

(a) a machinery aid

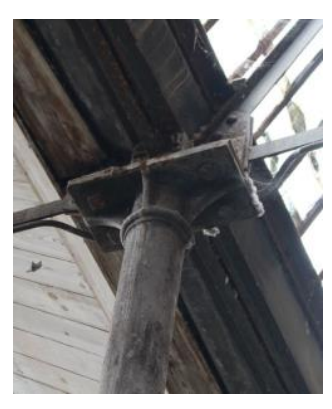

(b) decoration and square bolts

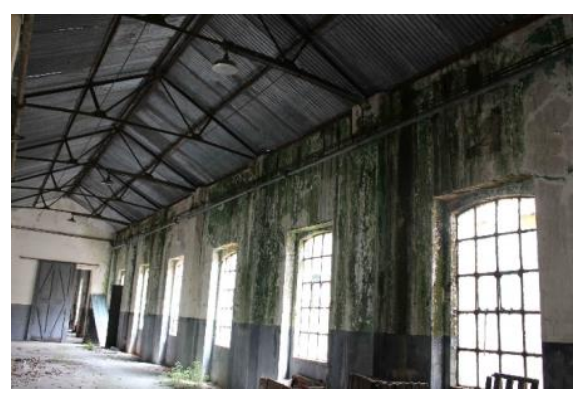

(d) Corrugated steel roof (a) left exposed in a workshop space

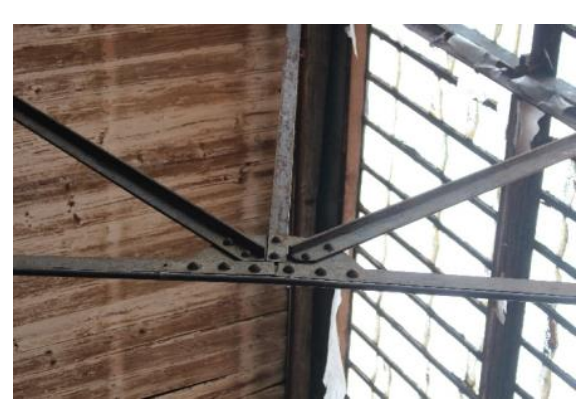

(c) Flat and angle-shaped members in the roof truss with riveting

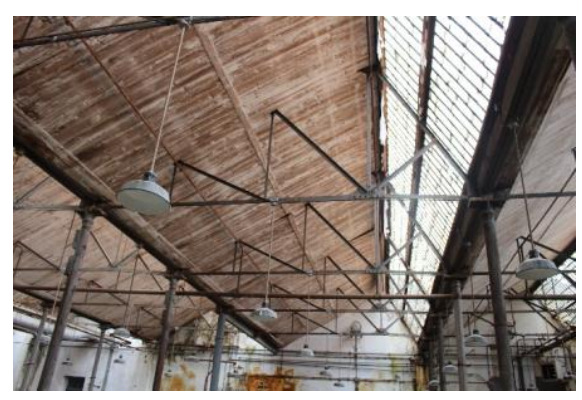

(e) Corrugated steel roof covered by wood paneling in the main rooms

Figure 6 - Cast iron detailing for columns $(a, b)$ and Roof detailing (c, d, e)

Krichko, Kori; Valente, Isabel B. (2018)

Fábrica do Paleão: Structural Assessment of Iron in Portugal's Industrial Heritage.

Paper submitted to Proceedings of the Institution of Civil Engineers -

Engineering History and Heritage, ISSN 1757-9430. 
The most obvious cast iron indicator is the complex shape of the column, most evident at the column head with fluting and classical details present. Additionally, some of the columns appear to have been customized at the top as shown with the two box-type elements, likely supporting machinery or other industrial activity at the site. These unique shapes can only be obtained by the casting with custom molds. Cast iron is manufactured by pouring molten iron with a high carbon content, between 2 and 5 percent, into molds to cool and solidify (GSA, 1998a). In nearly all of the columns, 2 strips are running longitudinally at 180 degrees from each other. This irregularity marks the junction of two half-molds. The date of construction in 1891 , when cast iron was still commonly used for columns, confirms these visual indicators.

\section{Beams and Roof Trusses}

Due to the age, shape and structural applications the roof trusses and beams spanning perpendicular are likely wrought iron (GSA, 1998b).

Cast iron's weakness in tension and compression made it an unpopular choice for beams and truss members in compression. The shapes of the members are another visual distinction from cast iron. Wrought iron trusses traditionally employed flat members in tension and angles or Tshaped elements in compression as seen at the site. The regular I-beam section is indicative of either wrought iron or mild steel.

Distinguishing between steel and wrought iron for these applications is more difficult. The construction of the factory falls also falls within the overlapping period of 1880 and 1900 where both steel and cast iron were utilized. Additionally, early steel members copied wrought iron's design making visual distinctions nearly impossible. In this case, sampling would be required to make a definite identification. For the analysis, wrought iron values were conservatively assumed.

\subsection{Damage identification}

To summarize the damages identified and explained in the previous sections, a table has been compiled in Table 2. The information is organized by the structural component and provides the key damages and the cause assumed by visual inspection.

Despite unique effects on each structural element due to varying materials and locations, the damages appear to be the result of a few common causes. The presence of moisture is apparent

Krichko, Kori; Valente, Isabel B. (2018)

Fábrica do Paleão: Structural Assessment of Iron in Portugal's Industrial Heritage.

Paper submitted to Proceedings of the Institution of Civil Engineers -

Engineering History and Heritage, ISSN 1757-9430. 
in nearly all of the structural elements studied in the visual inspection. Broken glass panes at the roof and a deteriorated drainage system allow water to enter from the top of the structure causing many of the vegetation patterns noted along the upper section of the walls and drainage paths and the corrosion at the column heads. While concentrated in these areas, the moisture is spread throughout the structure allowing vegetation growth in the slab and corrosion of the column shafts. The moisture rising from the ground is also impacting the masonry walls in the structure. The majority of these damages can be attributed to a general lack of maintenance since the factory was closed in 1994.

Table 2 - Summary table of the damages identified in the factory during the visual inspection

\begin{tabular}{|c|c|c|c|c|}
\hline \multicolumn{2}{|c|}{ Structural component } & Damages identified & Location/distribution & Probable cause \\
\hline \multirow{3}{*}{\multicolumn{2}{|c|}{ Floor slab }} & Regular discontinuities & Room B & $\begin{array}{l}\text { Removal of piping or other } \\
\text { mechanical systems }\end{array}$ \\
\hline & & Vegetation & Global damage & $\begin{array}{l}\text { Moisture present, } \\
\text { deterioration of the slab }\end{array}$ \\
\hline & & Cracking & Refer to columns & Refer to columns \\
\hline \multirow{2}{*}{\multicolumn{2}{|c|}{ Exterior walls }} & Spalling & 1 meter from the ground & Efflorescence and rising damp \\
\hline & & Black crust & $\begin{array}{l}\text { Along the roofline and } \\
\text { along the gutter systems }\end{array}$ & $\begin{array}{l}\text { Moisture from damaged or } \\
\text { improper } \\
\text { systems }\end{array}$ \\
\hline \multirow{3}{*}{\multicolumn{2}{|c|}{ Interior walls }} & Spalling & 1 meter from the floor & Efflorescence and rising damp \\
\hline & & Vegetation & Along the roofline & $\begin{array}{l}\text { Moisture from damaged or } \\
\text { improper } \\
\text { systems }\end{array}$ \\
\hline & & Red stains & $\begin{array}{l}\text { Evenly spaced areas along } \\
\text { west wall of Room A }\end{array}$ & $\begin{array}{l}\text { Moisture and interior } \\
\text { corroding elements }\end{array}$ \\
\hline \multirow{7}{*}{\multicolumn{2}{|c|}{ Cast iron columns }} & Cracks in slab & $\begin{array}{l}\text { Frequently from the base } \\
\text { of column }\end{array}$ & $\begin{array}{l}\text { Expansion of embedded } \\
\text { column due to corrosion }\end{array}$ \\
\hline & & Flaking & $\begin{array}{l}\text { Frequent in the middle of } \\
\text { the shaft in Room B }\end{array}$ & Corrosion due to the moisture \\
\hline & & Blowholes & On the shaft & Casting defects and corrosion \\
\hline & & Spots & On the shaft & $\begin{array}{l}\text { Past usage, casting defects } \\
\text { and corrosion }\end{array}$ \\
\hline & & Discoloration & $\begin{array}{l}\text { Of the shaft in a few } \\
\text { elements }\end{array}$ & Moisture \\
\hline & & Corrosion & $\begin{array}{l}\text { Frequent in the column } \\
\text { heads }\end{array}$ & $\begin{array}{l}\text { Accumulation of moisture due } \\
\text { to shape and location }\end{array}$ \\
\hline & & Missing bolts & $\begin{array}{l}\text { In a few of the column } \\
\text { heads }\end{array}$ & Corrosion due to moisture \\
\hline \multicolumn{2}{|c|}{$\begin{array}{l}\text { Wrought } \quad \text { iron } \\
\text { elements }\end{array}$} & Some corrosion & Mainly in adjacent beams & Moisture below \\
\hline \multirow[t]{2}{*}{ Roof } & $\begin{array}{l}\text { Corrugated } \\
\text { metal }\end{array}$ & $\begin{array}{ll}\text { Some } & \text { superficial } \\
\text { corrosion } & \\
\end{array}$ & - & Weathering effects \\
\hline & Glass Panes & $\begin{array}{l}\text { Broken or missing in some } \\
\text { areas }\end{array}$ & $\begin{array}{l}\text { Randomly distributed in } \\
\text { each room }\end{array}$ & Weathering effects \\
\hline
\end{tabular}

Krichko, Kori; Valente, Isabel B. (2018)

Fábrica do Paleão: Structural Assessment of Iron in Portugal's Industrial Heritage.

Paper submitted to Proceedings of the Institution of Civil Engineers -

Engineering History and Heritage, ISSN 1757-9430. 


\section{IN SITU TESTING}

By completing an in depth visual and historical investigation, it was possible to determine the geometry and the main culprit of the damages observed in the factory. The lack of maintenance and presence of moisture throughout the structure has impacted the masonry walls, concrete slab and metallic structural elements in various ways. While all elements were measured and assessed during the visual inspection, the remainder of the investigation focuses on the interior metal structure. Available non-destructive and minor destructive testing methods were employed to obtain additional geometric information and to assess the severity and impact of the damages.

The procedures and results of the in situ tests performed are described in the proceeding section. Maintaining the damage survey column numbering, the columns tested are marked in Figure 7.a.

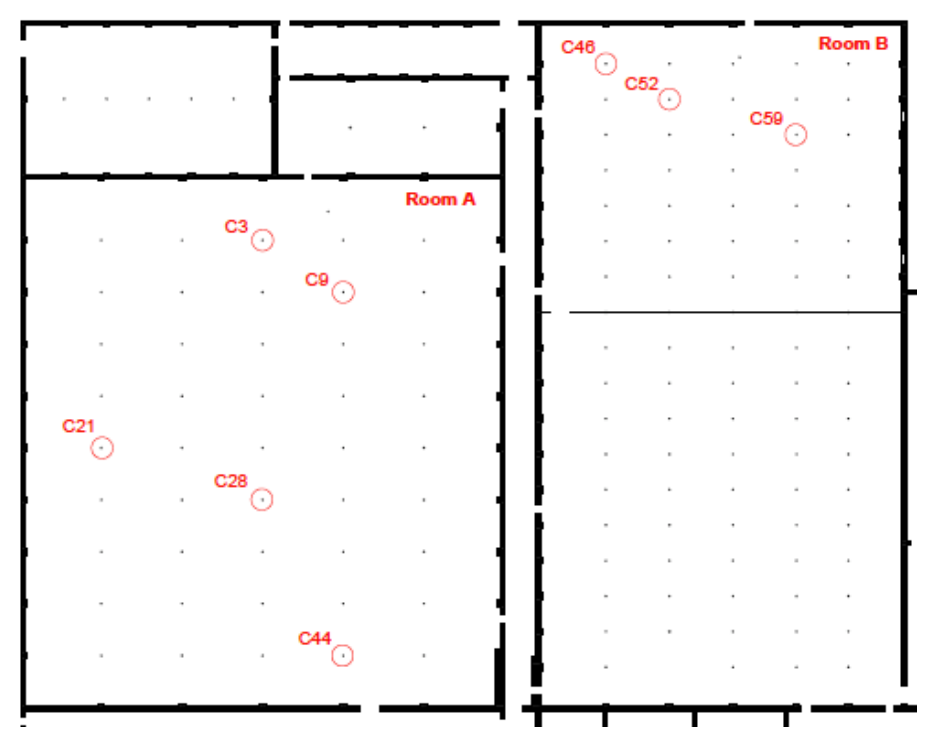

(a)

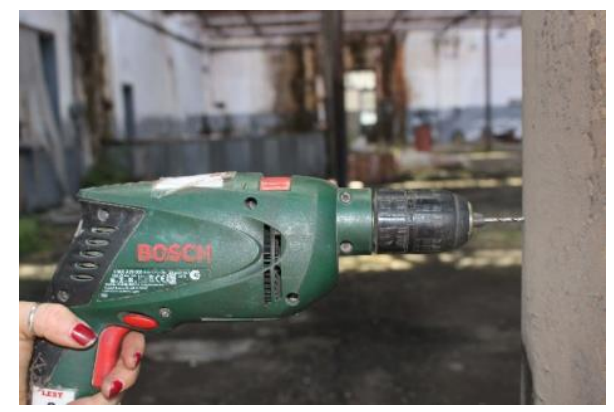

(c)

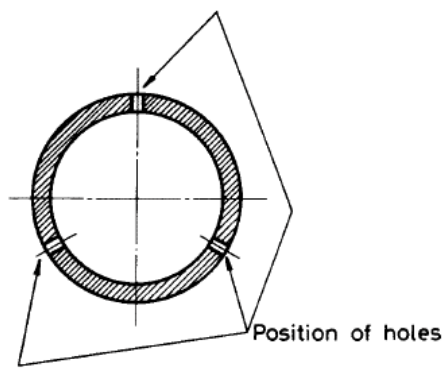

(b)

Krichko, Kori; Valente, Isabel B. (2018)

Fábrica do Paleão: Structural Assessment of Iron in Portugal's Industrial Heritage.

Paper submitted to Proceedings of the Institution of Civil Engineers -

Engineering History and Heritage, ISSN 1757-9430. 


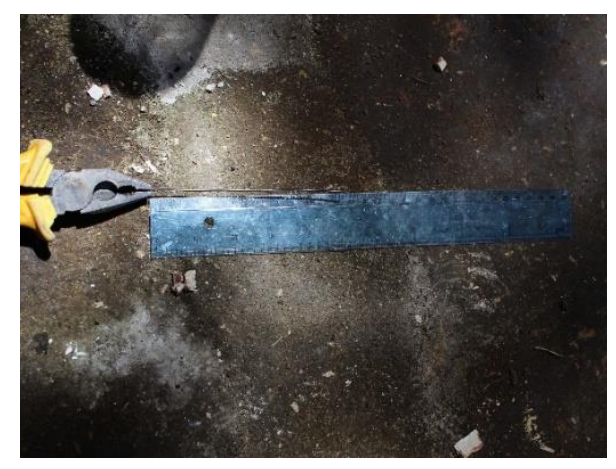

(e)
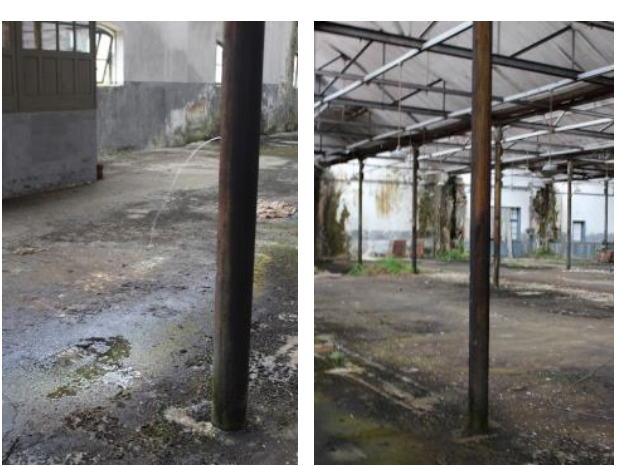

(f)

Figure 7 - (a) Location of tested columns; (b, c, d and e) Wall thickness measurement (Bussell, 1997): infield demonstration of the procedure to measure the column thickness; ( $f$ ) Water pouring out from the hole drilled and full discoloration of Column 6

\subsection{Column drilling}

\subsubsection{Background and objective}

The most common cast iron column is the hollow circular section. Without standardization in the manufacturing process or building codes and regulations, the wall thickness of the columns is often unknown. The casting process also produced a number of irregularities or deformities including eccentricity in the outer and inner diameter of the column that cannot be visually detected. A minor destructive drilling test was performed in multiple columns in Fábrica do Paleão to establish the cross-sectional area of the cast iron columns representative of all the interior cast iron columns. The results obtained provide key geometrical input data for further analysis and allow the detection of eccentricities or other casting deformities in the columns.

\subsubsection{Procedure}

The subsequent procedure describes the process of obtaining wall thickness measurements for hollow columns:

1. Drill three holes spaced evenly (about 120 degrees) about the center at slightly varying elevations to avoid weakening the element. Drilling locations can be viewed in Figure 7.b

2. Measure and record the column circumference at each of the levels the holes are drilled to calculate the diameter at each drilling location (Figure 7.c).

Krichko, Kori; Valente, Isabel B. (2018)

Fábrica do Paleão: Structural Assessment of Iron in Portugal's Industrial Heritage.

Paper submitted to Proceedings of the Institution of Civil Engineers -

Engineering History and Heritage, ISSN 1757-9430. 
3. Insert the straight wire into each of the holes drilled with pliers until it reaches the opposite wall of the column (Figure 7.d).

4. Measure the amount of wire that could be inserted into the column (Figure 7.e).

5. Subtract the length of inserted wire from the diameter to determine the wall thickness at each location.

6. Repeat procedure for additional columns (7 in total).

\subsubsection{Results and Discussion}

Following the procedure, 7 of the 128 remaining columns in main rooms were measured during two site visits. Measurements are listed and averaged in Table 3.

Table 3 - Cast iron column section measurements

\begin{tabular}{|c|c|c|c|c|c|c|c|}
\hline $\begin{array}{l}\text { Column } \\
\text { [ID] }\end{array}$ & $\begin{array}{l}\text { Drilled } \\
\text { hole }\end{array}$ & $\begin{array}{l}\text { Outer } \\
\text { diameter } \\
(\mathrm{mm})\end{array}$ & $\begin{array}{l}\text { Average } \\
\text { outer } \\
\text { diameter } \\
(\mathrm{mm})\end{array}$ & $\begin{array}{l}\text { Wall } \\
\text { thickness } \\
(\mathrm{mm})\end{array}$ & $\begin{array}{l}\text { Average } \\
\text { wall } \\
\text { thickness } \\
(\mathrm{mm})\end{array}$ & $\begin{array}{l}\text { Standard } \\
\text { deviation }\end{array}$ & $\begin{array}{l}\text { Coefficient of } \\
\text { variation }\end{array}$ \\
\hline \multirow[t]{3}{*}{1 [C9] } & 1 & 155 & \multirow[t]{3}{*}{154.33} & 21.4 & \multirow[t]{3}{*}{20.37} & \multirow[t]{3}{*}{1.38} & \multirow[t]{3}{*}{$6.8 \%$} \\
\hline & 2 & 155 & & 18.8 & & & \\
\hline & 3 & 153 & & 20.9 & & & \\
\hline \multirow[t]{3}{*}{$2[\mathrm{C} 3]$} & 1 & 156 & \multirow[t]{3}{*}{154.67} & 17.8 & \multirow[t]{3}{*}{18.07} & \multirow[t]{3}{*}{1.62} & \multirow[t]{3}{*}{$8.9 \%$} \\
\hline & 2 & 155 & & 19.8 & & & \\
\hline & 3 & 153 & & 16.6 & & & \\
\hline $3[\mathrm{C} 46]$ & - & - & - & - & - & - & - \\
\hline \multirow[t]{3}{*}{4 [C52] } & 1 & 155 & \multirow[t]{3}{*}{155.00} & 20.1 & \multirow[t]{3}{*}{17.77} & \multirow[t]{3}{*}{2.52} & \multirow[t]{3}{*}{$14.2 \%$} \\
\hline & 2 & 155 & & 15.1 & & & \\
\hline & 3 & 155 & & 18.1 & & & \\
\hline \multirow[t]{3}{*}{5 [C59] } & 1 & 152 & \multirow[t]{3}{*}{152.00} & 17.9 & \multirow[t]{3}{*}{17.57} & \multirow[t]{3}{*}{1.53} & \multirow[t]{3}{*}{$8.7 \%$} \\
\hline & 2 & 152 & & 15.9 & & & \\
\hline & 3 & 152 & & 18.9 & & & \\
\hline $6[\mathrm{C} 21]$ & 1 & 154 & - & 19.9 & - & - & - \\
\hline \multirow[t]{3}{*}{7 [C28] } & 1 & 155 & \multirow[t]{3}{*}{155.00} & 16.8 & \multirow[t]{3}{*}{16.80} & \multirow[t]{3}{*}{1.00} & \multirow[t]{3}{*}{$6.0 \%$} \\
\hline & 2 & 155 & & 17.8 & & & \\
\hline & 3 & 155 & & 15.8 & & & \\
\hline \multicolumn{2}{|l|}{ Average } & - & 154.2 & - & 18.1 & - & - \\
\hline \multicolumn{2}{|c|}{ Standard deviation } & & 1.261 & & 1.344 & & \\
\hline \multicolumn{2}{|c|}{ Coefficient of variation } & & $0.8 \%$ & & $7.4 \%$ & & \\
\hline
\end{tabular}

For each column the thickness of the wall was calculated for each hole drilled. With the wall thickness and outer diameter an internal diameter and cross-sectional area was computed for each location. To estimate the cross-sectional area of each column, an average value was determined from the three holes drilled. For analysis, values from 5 of the 7 columns tested were considered, as it was not possible to gather 3 measurements for the remaining 2 columns due to interior corrosion and the presence of water.

Krichko, Kori; Valente, Isabel B. (2018)

Fábrica do Paleão: Structural Assessment of Iron in Portugal's Industrial Heritage.

Paper submitted to Proceedings of the Institution of Civil Engineers -

Engineering History and Heritage, ISSN 1757-9430. 
To test the eccentricity, the wall thickness at each location was compared with the mean wall thickness of each member by analyzing the values of the coefficient of variation associated with the thickness of each tested column. With the exception of column 4 , all percentages computed were less than 10 percent. This implies the wall thickness is relatively constant without significant eccentricities detected for the majority of the columns. For column 4 the coefficient of variation reached 14.2 percent. This is the result of the $5 \mathrm{~mm}$ difference between 2 of the measured wall thicknesses in this column, which was the largest difference detected in any of the measured columns. In this case the column may be considered slightly eccentric.

Beyond obtaining necessary geometrical parameters and eccentricity detection, the drilling provided insight on the internal condition of the columns with various surface damages identified during the visual inspection. A visual inspection of column 3 revealed an external layer of corrosion and the presence of blowholes. Column 6 was noted as fully discolored, as depicted in Figure 7.f. Upon the removal of the drill form the first hole, water began to pour out of the opening. The stream of water displayed in Figure 7.f continued for a significant amount of time suggesting the interior of the column was full of water until the test was performed. It was decided not to continue drilling to avoid further compromising the column, but it was possible to gain one measurement. The wall thickness at this location was determined to be $19.9 \mathrm{~mm}$, a value slightly higher than the average wall thickness of $18.1 \mathrm{~mm}$. It is expected the section would increase with corrosion, however the wall thickness is not significantly higher than the average computed for the other tested columns. Despite the presence of water, the section does not appear to be significantly impacted. With the result of this test, it is also suspected that the full discoloration noted in a number of other columns, could be the result of water in the interior of the element.

\subsection{Hardness test}

\subsubsection{Background and objectives}

Hardness testing is a non-destructive technique to directly determine the hardness of the material, or its resistance to permanent deformation under loading. Hardness values can also indirectly determine a number of other metallic properties including tensile strength, yield strength and fatigue behavior through established empirical relationships. For assessing heritage structures

Krichko, Kori; Valente, Isabel B. (2018)

Fábrica do Paleão: Structural Assessment of Iron in Portugal's Industrial Heritage.

Paper submitted to Proceedings of the Institution of Civil Engineers -

Engineering History and Heritage, ISSN 1757-9430. 
with metallic structural elements, the ultimate tensile capacity is a key strength parameter. To avoid sampling and laboratory testing, the hardness test is a non-destructive option for indirect strength measurements. When possible, hardness values should be calibrated with samples of known strength.

To perform the hardness test on the cast iron columns in the spinning and weaving sections of the factory, the Procep Equotip Bambino equipment was selected. This portable device is designed for the LEEB rebound method established by Proceq. The rebound method measures and compares the energy in the impact body before and after the force is applied, providing the result in a hardness unit through Equation (1) (Proceq, 2015),

$$
H L=\frac{\text { velocity rebound }}{\text { velocity impact }} \times 1000
$$

where the higher values correspond with greater rebound velocities and ultimately hardness of the material. This value can be converted to different scales or adjusted by navigating the operating levels detailed in the operating manual. Prior to launching the test, the hardness scale was converted to the Brinell scale and the material group was selected.

\subsubsection{Results and Analysis}

Following the procedure described in the previous section, hardness measurements were taken in the Brinell conversion scale for columns marked in Figure 7. These locations were selected by accessibility to power on the day of testing. For each selected column, 4 areas were cleaned and 5 tests were performed for each area, totaling 20 tests per column.

A number of known sources of error for this type of testing and observations during the test created some variability in the results. The main sources of variation are the result of human error due to handling the device and improperly cleaning the surface. Variations in the material itself can also increase error. To account for variability, the data was treated by disregarding any values greater than 12 percent from the average measurement of each column.

Table 4 has been included to assess the reliability of the results and compare the treated and raw data. While the minimum and maximum values appear to have a high variation from the mean, the standard deviation is considerably lower and with the slight exception of column 1 , the coefficient of variation is less than 10 percent for the raw data. This measure of dispersion was

Krichko, Kori; Valente, Isabel B. (2018)

Fábrica do Paleão: Structural Assessment of Iron in Portugal's Industrial Heritage.

Paper submitted to Proceedings of the Institution of Civil Engineers -

Engineering History and Heritage, ISSN 1757-9430. 
decreased to an acceptable value for each column by data treatment. The treatment also reduced the standard deviation, increasing the precision. While the treated values produce statistically superior results, treatment did not significantly alter the average measurements. Therefore, while the adjusted averages were considered for the empirical strength relations, using the raw average values did not significantly impact the final values.

Table 4 - Statistical analysis of the raw and treated data collected in the hardness test

\begin{tabular}{|l|c|c|c|}
\hline & Column 1 [C9] & Column 2 [C3] & Column 3 [C46] \\
\hline Maximum value & 243 & 211 & 265 \\
\hline Minimum value & 164 & 148 & 180 \\
\hline Maximum variation & 79 & 63 & 85 \\
\hline Average & 199.7 & 183.8 & 214.9 \\
\hline Standard deviation & 21.99 & 16.84 & 18.38 \\
\hline Coefficient of variation & $11.0 \%$ & $9.2 \%$ & $8.6 \%$ \\
\hline Treated Average & 200.7 & 186.0 & 216.1 \\
\hline Treated standard deviation & 14.80 & 12.23 & 9.52 \\
\hline Treated coefficient of variation & $7.4 \%$ & $6.6 \%$ & $4.4 \%$ \\
\hline Total Treated Average & & $\mathbf{2 0 0 . 9}$ & \\
\hline
\end{tabular}

Once the validity of the results was established, the results were correlated with other material properties. The hardness test is essentially a compression test measuring the hardness matrix and the volume and configuration of the graphite. To obtain an idea of the matrix microstructure around the flake graphite, the Brinell hardness values obtained from the three columns were compared with reference values provided in the bibliography (AFC, 2015). The average treated value of the three columns falls in the higher strength gray iron category with a fine pearlite microstructure. It should be noted that the values are at the low end of the range. An individual assessment of each column gives a different result for column 2. At a value of 186 , column 2 is within the range for ordinary gray iron with a pearlite and ferrite matrix microstructure. The average of all 3 columns rests at the border of an ordinary and high strength cast iron.

Cast iron is generally classified by its tensile strength, highly dependent on the amount of graphite. Therefore, it is possible to relate tensile strength and hardness to estimate the tensile strength of cast iron. Figure 8 has been included and marked with the treated average value to determine an estimated value for the tensile strength.

Krichko, Kori; Valente, Isabel B. (2018) 
The graphs relating hardness and tensile strength are from of a study originally published in 1969 (Krause, 1969), which provides one of the most complete hardness studies for gray cast iron.

To demonstrate the variability in testing and dependence on the size of the sample, the results of two studies with two test bars diameter ranges have been provided. Figure 8.a is the result of tests on $7 / 8$ to 1.2 inches (approximately 22 millimeter to 30 millimeter) in diameter and Figure 8.b is the result of tests on $7 / 8$ to 6 inches (approximately 22 millimeter to 152 millimeter) in diameter. A conservative regression line labeled SAE is drawn in each figure, representing minimum Brinell hardness values being considered by the SAE Division 9 ISTC Committee (Krause, 1969). While the scatter varies between the two diameter ranges, the approximated tensile strength from each is essentially the same, approximately $23 \mathrm{kgf} / \mathrm{mm}^{2}$, or $230 \mathrm{MPa}$.

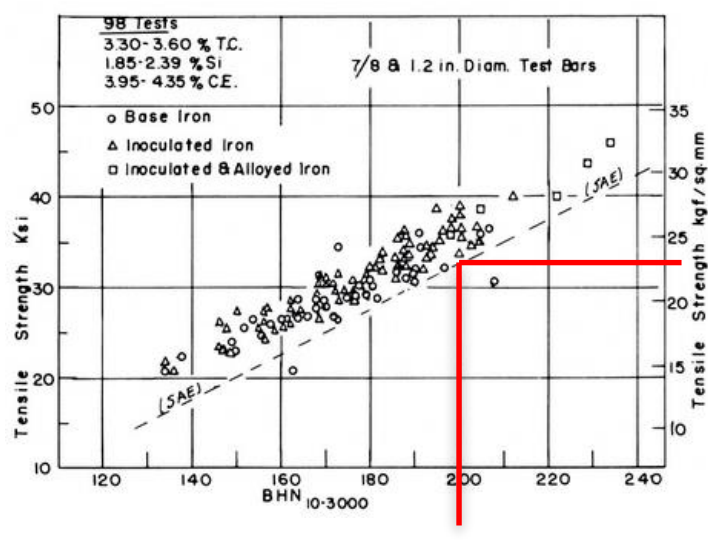

(a)

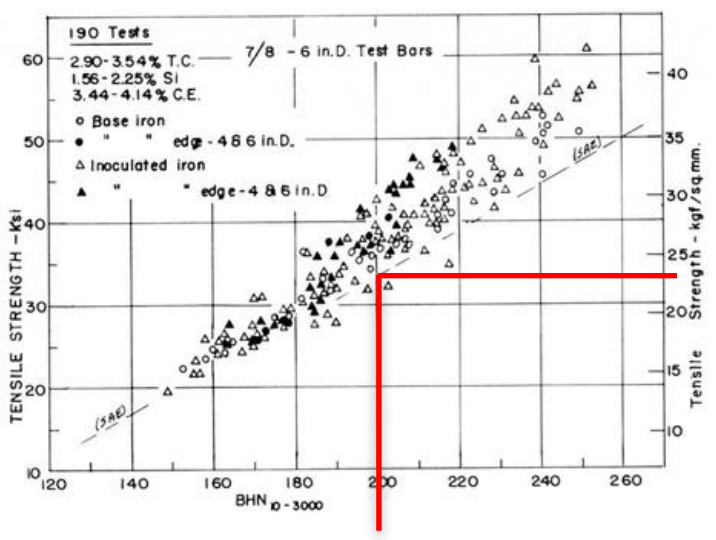

(b)

Figure 8 - Brinell hardness-tensile strength relationship for Foundry F (Krause, 1969)

\section{STRUCTURAL ANALYSIS AND SAFETY ASSESSMENT}

\subsection{Introduction}

An in depth visual inspection and in situ testing reveal that despite the global presence of moisture, the structure appears to be adequately supporting the present loads. To ensure the longevity of the factory, it would be advantageous to find an alternative purpose and encourage a regular use and maintenance of the structure. Therefore, a structural analysis and safety assessment was performed to confirm its present condition and assess its adequacy for future uses. Due to the repetitive nature of the internal metallic structure, it was possible to create a two-

Krichko, Kori; Valente, Isabel B. (2018)

Fábrica do Paleão: Structural Assessment of Iron in Portugal's Industrial Heritage.

Paper submitted to Proceedings of the Institution of Civil Engineers -

Engineering History and Heritage, ISSN 1757-9430. 
dimensional analysis of a single frame that is representative of the structure in each of the two main rooms. Geometric and material properties were gathered from previously collected values with loads estimated from modern Eurocode guidelines.

\subsection{Building the Model}

\subsubsection{Geometry}

Due to the repetitive structural design in the factory, only one frame in each of the main rooms was modeled. The input measurements for each frame shown in Figure 9.a and in Figure 9.b were taken from the geometric survey. The frames have the same height and geometric configuration, but differ in length. As depicted in the plan of the structure, the spacing between frames also varies between rooms $A$ and $B$, where the distance between trusses in room $A$ measures $4.90 \mathrm{~m}$ and $3.35 \mathrm{~m}$ for room $\mathrm{B}$.

Room A

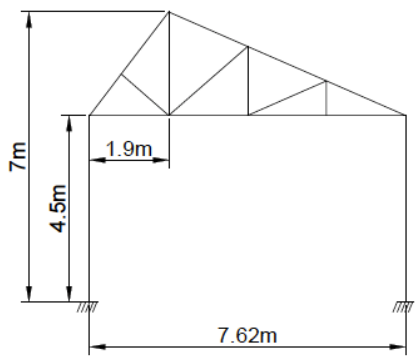

(a) Room A
Room B

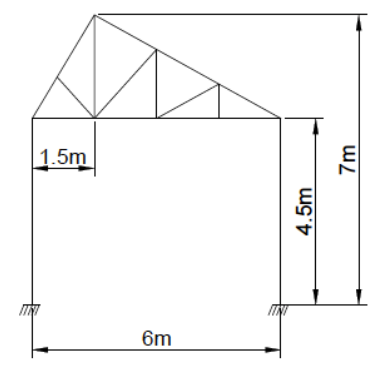

(b) Room B
All Fixed

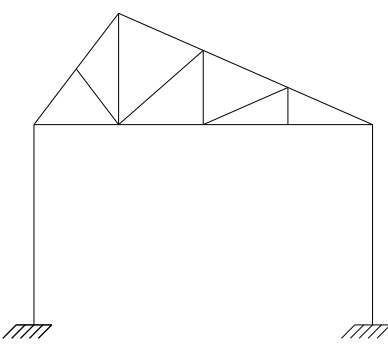

(c) All Fixed model
All Hinged (Released)

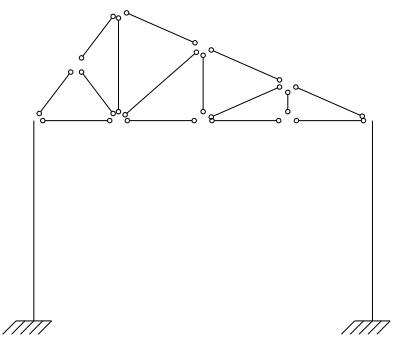

(d) All Hinged model
"Real" Model

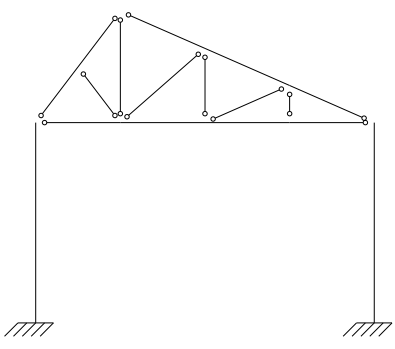

(e) "Real" model

Figure 9-Geometric configuration of the frames modeled in rooms A and B and connection combinations tested

Krichko, Kori; Valente, Isabel B. (2018) 


\subsubsection{Material properties and cross sections}

The two materials identified in the frames were cast and wrought iron. For each model, cast iron was assigned to the columns and wrought iron to the truss elements. The material properties were selected from the range of typical material values provided in in the bibliography, (Bussel, 1997) and (Verhoef, 1999). The exact input values are listed in Table 5.

During the geometrical survey, the dimensions of the columns and each of the truss members were measured. Average section values, from on-site caliper measurements, are tabulated in Table 1. These measurements were entered into SAP2000 to create a wrought iron frame sections for each of the truss members. With the exception of the double C-section in the bottom chord in room $\mathrm{A}$, all compression members are $\mathrm{T}$-bar sections and all tensile members are flat bars, as illustrated in Figure 4. Average circumference and wall thickness for the cast iron columns were taken from in situ tests results listed in Table 3.

Table 5 - Material property input values

\begin{tabular}{|l|c|c|}
\cline { 2 - 3 } \multicolumn{1}{c|}{} & Cast Iron & Wrought Iron \\
\hline Weight per unit volume $\left(\mathrm{kN} / \mathrm{m}^{3}\right)$ & 72 & 76 \\
\hline Young's modulus, $\mathrm{E}(\mathrm{GPa})$ & 85 & 200 \\
\hline Poisson's ratio, $v$ & 0.25 & 0.25 \\
\hline
\end{tabular}

\subsubsection{Connections: Sensitivity Analysis}

During the visual inspection, all of the connections in the frame were observed in an attempt to select the most accurate joints for the model. In this approximation, the imbedded columns are assumed fixed, while the remaining joints are fixed or hinged depending on the continuity of the truss members. Continuous members, such as the top chords, are modeled as fixed, while the ends of members are assumed hinged. These assumptions are represented in the scenario labeled "real" model in Figure 9.e.

This model is approximate, as it is difficult to estimate exactly how observed connections will behave. To account for this uncertainty, a sensitivity analysis was performed to quantify the effect of the selection of various connections. With particular attention to fixed or hinged joints, the three scenarios depicted in see Figure 9.c, Figure 9.d and Figure 9.e were tested. As illustrated, the "real" model assumed to be the closest to reality, is between the two extreme cases of all hinged

Krichko, Kori; Valente, Isabel B. (2018)

Fábrica do Paleão: Structural Assessment of Iron in Portugal's Industrial Heritage.

Paper submitted to Proceedings of the Institution of Civil Engineers -

Engineering History and Heritage, ISSN 1757-9430. 
(released) and all fixed, where continuous members are modeled as fixed at the joint and members that terminate at a joint are assumed hinged. This analysis tested the difference between the proposed model and the two extremes to define any necessary adjustments in the stress values obtained with the "real" model during further safety analysis.

Assuming the connections in the two frames tested act similarly, the sensitivity analysis was only performed on the 6-meter truss in room B. As depicted in Figure 10, a load $P$ was applied at joints $B, D, E$ and $G$.

The resulting axial forces and bending moments were recorded in terms of the load value, $P$, for each of the scenarios. Finally, the differences between the "real" and the all hinged and all fixed scenarios were calculated to compute necessary adjustments for the safety analysis.

When the "real" and "all hinged" models are compared, the maximum difference between the all hinged and the "real" model is -4 percent. This indicates the variance between the real model and the two extreme cases is small. For the safety analysis the small difference will be accounted for by increasing the axial forces acting on the "real" model by 5 percent to ensure the stability of the structure if all the connections were to act as hinged joints.

The same scenarios were modeled to compare bending moments. As expected, with the exception of the fixed columns, the all hinged scenario produced no bending moments in the members and the all fixed resulted in the highest values. Therefore, the bending moment comparison focused on the difference between the all fixed and the "real" model. Due to the structural behavior of trusses, the bending moments are typically minimal, making slight differences appear significant. As a result of these minimal or nonexistent bending moments, the adjustment bending moments was resolved in a different manner. The analysis shows that the chords, or the external truss members, produced larger bending moments than the webs, or internal truss members. To adjust for any differences in the joints assumed, the acting bending moments were altered in the safety analysis according to these maximum values in the all fixed model. The bottom and top chords were considered 2 percent of the load applied and the acting bending moments in the truss webs were adjusted by 0.8 percent.

Krichko, Kori; Valente, Isabel B. (2018)

Engineering History and Heritage, ISSN 1757-9430. 


\subsection{Structural Assessment}

After constructing the models of the frames in rooms $A$ and $B$ according to the parameters defined previously, the present loads were estimated and applied to the model. The axial forces and bending moments induced by two load scenarios, considering the presence and absence of wind, were determined and analyzed to assess the present structural capacity of the frames modeled.

\subsubsection{Load Cases}

The three load cases considered for the frames modeled in the factory were dead loads, roof live loads and wind loads. These loads were established following the guidelines of Eurocode 1 where each load case is unique to each load type, and the geometry of the structure (CEN, 2002), (CEN, 2005a).

The dead loads were computed considering the frame itself, the glass paneling applied to the steep slope and the corrugated metal and wood paneling covering the gradual slope, and also the nonstructural materials in the ceiling and roof. The distribution of these loads is illustrated in Figure 10a. The dead weight produced by the frame itself was calculated and applied automatically by the frame section properties in SAP2000.

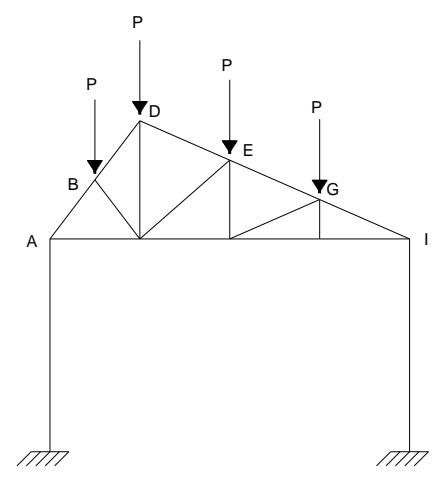

(a) Load application in the trusses

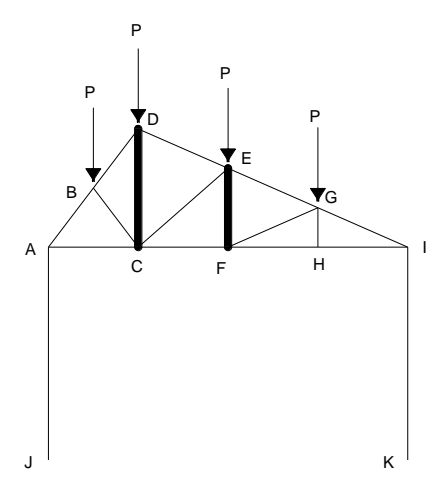

(b) Truss of Room A

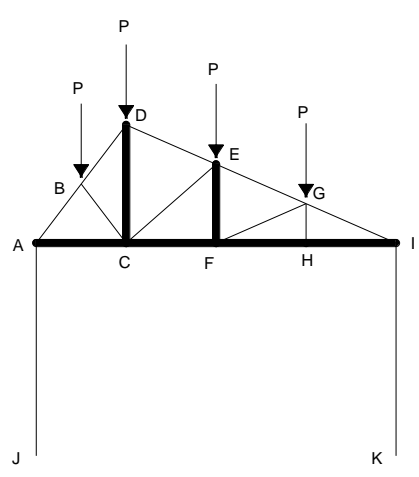

(c) Truss of Room B

Figure 10 - Load application in the trusses and identification of unsafe bars

Krichko, Kori; Valente, Isabel B. (2018) 
To account for loads applied during regular maintenance, a roof live load was estimated assuming the structure to be category $\mathrm{H}$, defined by EN 1991-1-1 (CEN, 2002) as accessible for normal maintenance and repair only. The imposed load value, $q_{k}$, ranges from 0 to $1 \mathrm{kN} / \mathrm{m}^{2}$. For this application the recommended value of $0.4 \mathrm{kN} / \mathrm{m}^{2}$ was applied.

Wind loads were determined following procedures in EN 1991-1-4 (CEN, 2005a) accounting for the location, exposure and geometry of the structure. Due to the repeated shed roof structure in the factory, multiple values were determined based on location. To simplify and attain a single value for the safety evaluation, the worst of these scenarios was selected.

All individual distributed load case values are included in Table 6. These distributed loads were translated to point loads applied at the joints on the top chords of the truss. This simplifies the application of loads for a two-dimensional model of a three-dimensional structure. Additionally, point application imitates the actual structure, as the joint locations often align with the lateral support elements resting under the roofing system.

Table 6 - Load case values given as uniformly distributed loads applied to the roof surface

\begin{tabular}{|c|c|c|c|c|}
\hline Action & \multicolumn{2}{|l|}{ Load case } & $\begin{array}{l}\text { Uniformly } \\
\text { distributed load } \\
\left(\mathrm{kN} / \mathrm{m}^{2}\right)\end{array}$ & $\begin{array}{l}\text { Net distributed load } \\
\left(\mathrm{kN} / \mathrm{m}^{2}\right)\end{array}$ \\
\hline \multirow[t]{3}{*}{$\begin{array}{l}\text { Permanent } \\
\text { action, } g_{k}\end{array}$} & \multirow[t]{3}{*}{ Dead load } & $\begin{array}{l}\text { Corrugated steel and metal } \\
\text { support beams }\end{array}$ & 0.2 & \multirow[t]{2}{*}{0.30} \\
\hline & & Decorative timber panelling & 0.1 & \\
\hline & & $\begin{array}{l}\text { Glass panes with metallic } \\
\text { support }(6 \mathrm{~mm} \text { thick })\end{array}$ & 0.35 & 0.35 \\
\hline $\begin{array}{l}\text { Imposed } \\
\text { action, } \mathrm{q}_{\mathrm{k}}\end{array}$ & \multicolumn{2}{|c|}{ Roof live load } & 0.4 & 0.4 \\
\hline \multirow{2}{*}{$\begin{array}{l}\text { Wind pressure, } \\
\mathrm{W}_{\mathrm{k}}\end{array}$} & \multicolumn{2}{|l|}{ Internal } & -6.23 & \multirow[t]{2}{*}{-4.69} \\
\hline & \multicolumn{2}{|l|}{ External } & 1.54 & \\
\hline
\end{tabular}

Locations of the point load applications are marked in Figure 10.a. Individual load case values added to the frames in rooms A and B are presented in Table 7.

Loads combinations were determined considering two scenarios. The first case assumes the absence of wind accounting only for the dead weight, $G_{k}$, and the roof live load, $Q_{k}$, as presented by Equation (2). The second combination considers the dead load and presence of wind, W, without live load, as presented by Equation (3). Load cases were combined and factored according to the following load combination formulas defined in the Eurocode (CEN, 2002).

Krichko, Kori; Valente, Isabel B. (2018)

Fábrica do Paleão: Structural Assessment of Iron in Portugal's Industrial Heritage.

Paper submitted to Proceedings of the Institution of Civil Engineers -

Engineering History and Heritage, ISSN 1757-9430. 


$$
\begin{aligned}
& \text { Load combination } 1(L C 1)=1.35 G_{k}+1.5 Q_{k} \\
& \text { Load combination } 2(L C 2)=1.0 G_{k}+1.5 \mathrm{~W}
\end{aligned}
$$

The point load values for each of the load cases and load combinations described are given in Table 7. Comparing the loads applied to the frames in rooms $A$ and $B$, it is evident that in all cases and combinations values the frames in room A are subject to greater loads. This is expected as the truss supports a greater roof area.

\begin{tabular}{|c|c|c|c|c|c|c|c|c|c|c|}
\hline \multirow{3}{*}{$\begin{array}{l}\text { Load } \\
\text { point }\end{array}$} & \multirow{2}{*}{\multicolumn{2}{|c|}{$\frac{\text { Dead load, } G_{k}}{[k N]}$}} & \multirow{2}{*}{\multicolumn{2}{|c|}{$\begin{array}{c}\text { Roof Live load, } Q_{k} \\
{[k N]}\end{array}$}} & \multirow{2}{*}{\multicolumn{2}{|c|}{$\begin{array}{c}\text { Wind load, W } \\
{[\mathrm{kN}]}\end{array}$}} & \multirow{2}{*}{\multicolumn{2}{|c|}{$\begin{array}{l}\text { LC1 } \\
{[\mathrm{kN}]}\end{array}$}} & \multirow{2}{*}{\multicolumn{2}{|c|}{$\begin{array}{l}\text { LC2 } \\
{[k N]}\end{array}$}} \\
\hline & & & & & & & & & & \\
\hline & $\begin{array}{c}\text { Room } \\
\text { A }\end{array}$ & $\begin{array}{c}\text { Room } \\
\text { B }\end{array}$ & $\begin{array}{c}\text { Room } \\
\text { A }\end{array}$ & Room B & $\begin{array}{c}\text { Room } \\
\text { A }\end{array}$ & Room B & Room A & $\begin{array}{c}\text { Room } \\
\text { B }\end{array}$ & Room A & Room B \\
\hline $\mathbf{P}_{\mathbf{A}}$ & 1.35 & 0.85 & 1.54 & 0.98 & -18.06 & -11.45 & 4.86 & 3.63 & -25.74 & -16.32 \\
\hline $\mathrm{P}_{\mathrm{B}}$ & 2.70 & 1.71 & 3.08 & 1.95 & -36.12 & -22.90 & 8.22 & 5.76 & -51.48 & -32.65 \\
\hline$P_{D}$ & 2.88 & 1.72 & 3.58 & 2.13 & -41.95 & -24.93 & 8.96 & 5.94 & -60.05 & -35.68 \\
\hline$P_{E}$ & 3.06 & 1.72 & 4.08 & 2.30 & -47.78 & -26.96 & 9.70 & 6.13 & -68.62 & -38.72 \\
\hline$P_{G}$ & 3.06 & 1.72 & 4.08 & 2.30 & -47.78 & -26.96 & 9.70 & 6.13 & -68.62 & -38.72 \\
\hline$P_{1}$ & 1.53 & 0.86 & 2.04 & 1.15 & -23.89 & -13.48 & 5.60 & 3.81 & -34.31 & -19.76 \\
\hline
\end{tabular}

Table 7 - Load point, $P$, values for each load case in each of the main rooms

\subsubsection{Analysis results}

After establishing loads, the model was run for the two load combinations considered. To visually compare the results of the scenarios, the axial force and bending moment diagrams have been provided in Table 8 for the two frames in each of the main rooms in the factory. The blue represents positive values (tensile stress and sagging bending moment) and the red is denotes negative values (compressive stresses and hogging bending moment).

Krichko, Kori; Valente, Isabel B. (2018)

Fábrica do Paleão: Structural Assessment of Iron in Portugal's Industrial Heritage.

Paper submitted to Proceedings of the Institution of Civil Engineers -

Engineering History and Heritage, ISSN 1757-9430. 
Table 8 - Force and bending moment diagrams for the truss in Room A and Room B

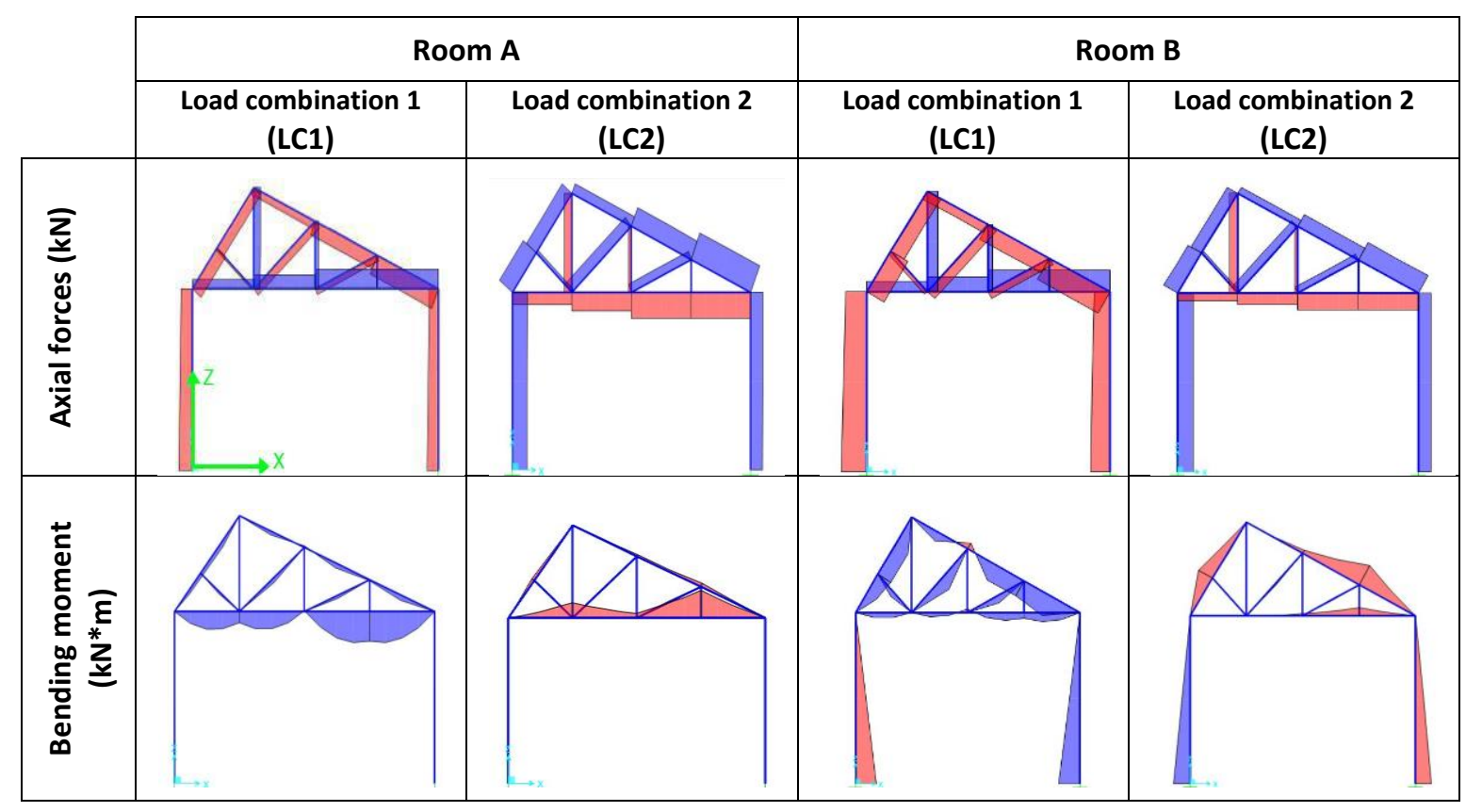

Due to the matching geometric configuration and nearly identical connection assignment, the axial force diagrams follow the same pattern for each of the load cases. Load combination 1, considering dead loads and roof live loads all acting in the negative $z$ direction, follows the intended design of the structure where all compression members are working in compression and all tensile members in tension. In the case of strong winds, modeled by load combination 2 , the internal wind pressures act in the positive $z$ direction imposing negative pressures to the frame, forcing compression members to act in tension and tensile members to act in compression.

For both trusses in each of the load combinations the greatest and most frequent bending moments are in the chords of the truss. However, for Room A the most apparent bending moments are concentrated in the bottom chords of the truss, where a stiff, continuous double cchannel section is implemented. Due to the opposing direction of the load combinations, the bending moments have opposite signs for each of the bending combinations with generally positive bending moments for the first combination and negative for the second. While these patterns are worthy of note, it should be emphasized that the bending moments are minimal in comparison to the axial forces due to the geometric configuration of the frame. With the exception of the columns, the frame is mainly acting as a truss designed to resist axial forces.

Krichko, Kori; Valente, Isabel B. (2018)

Engineering History and Heritage, ISSN 1757-9430. 
The stress values collected from the SAP model were adjusted by 1.05 to account for the extra stresses identified in the sensitivity analysis presented in section 5.2.3. Similarly, the additional bending moment values in chords were set equal to 2 percent of the $P$ values applied and the additional bending moment values in webs were set equal to 0.8 percent of the $P$ values applied. Axial force values in the columns were multiplied by 1.05 , however bending moment values were not adjusted.

\subsubsection{Safety Analysis}

A safety analysis was completed considering the bending moments and axial forces applied to each member of the frame, the material properties and frame sections. The buckling lengths of chords were considered equal to $1.0 \times \mathrm{L}$, both for in-plane and out-of-plane buckling. In the case of bottom chords of Truss A, bars $\mathrm{CF}$ and $\mathrm{FH}$ were analyzed with an out-of-plane buckling length that is equal to its double length $(L=3.81 \mathrm{~m})$, as there is no transversal bar in node $F$ that can prevent its lateral displacement. In the case of bottom chords of Truss B, there are no transversal bars in nodes $C, F$ or $H$ that can counteract their lateral displacement. Therefore, the corresponding buckling length is equal to 6.0 meters.

The value of tensile and compressive strength for the cast iron columns was assumed equal to $180 \mathrm{MPa}$ (after reducing the hardness test result by approximately 20 percent) and the value of tensile strength for the wrought iron elements in trusses was considered equal to $220 \mathrm{MPa}$ after the reduction factor is applied. This value was empirically established considering that the tensile strength in wrought iron is usually higher than $275 \mathrm{MPa}$.

The safety assessment is performed with the combined effect of axial forces and bending moments. The in-plane and the out-of-plane buckling effects are also accounted for. Equation (4), defined in EN 1993-1-1, is considered for the safety assessment calculation,

$$
\frac{N_{E d}^{*}}{\chi N_{R d}}+\frac{M_{y, E d}^{*}}{M_{y, R d}} \leq 1
$$

where,

$N_{E d}^{*}$ is the corrected axial force; $M_{E d}^{*}$ is the corrected bending moment; $N_{R d}$ is the resistant axial force; $M_{R d}$ is the resistant bending moment; and $\chi$ is the reduction coefficient that takes into account the buckling effects (if the member is in tension $\chi=1$ ).

Krichko, Kori; Valente, Isabel B. (2018)

Fábrica do Paleão: Structural Assessment of Iron in Portugal's Industrial Heritage.

Paper submitted to Proceedings of the Institution of Civil Engineers -

Engineering History and Heritage, ISSN 1757-9430. 
If the result given by Equation (4) is smaller than 1.0, then the safety verification of the corresponding element is satisfied.

The $\chi$ coefficient is calculated according to Equations (4) and (5).

$$
\begin{gathered}
\Phi=0.5\left[1+\alpha(\bar{\lambda}-0.2)+\bar{\lambda}^{2}\right] \\
\chi=\frac{1}{\Phi+\sqrt{\Phi^{2}-\bar{\lambda}^{2}}} \text { with } \quad \chi \leq 1.0
\end{gathered}
$$

According to EN 1993-1-1 (CEN, 2005b) the value of $\alpha$ is considered equal to 0.21 for circular hollow columns and equal to 0.49 for all other truss members.

After performing the safety assessment for each member and load combination, it was found that the safety conditions were not met for the members. In Room A bars $C D$ and $E F$ (both flat bars, marked with a thicker line in Figure 10.b) were considered considerably unsafe due to out-ofplane buckling and relatively unsafe due to in plane buckling.

In the trusses of Room $\mathrm{B}$, the safety condition was not met for bars $C D, E F, A C, C F, F H$ and $H I$ (marked with a thicker line in Figure 10.c). All bars that failed the safety assessment were flat bars in load case 2, where the main issue is buckling behavior. All other bars (T sections and channel sections) are considered safe.

\subsubsection{Vertical deflection}

One additional load case, LC3, was considered to evaluate the maximum vertical deflection in the trusses. Equation (7) presents the load combination coefficients considered in LC3.

$$
\text { Load combination } 3(\mathrm{LC} 3)=1.0 \mathrm{G}_{\mathrm{k}}+1.0 \mathrm{Q}_{\mathrm{k}}
$$

Table 9 presents the results gathered from the analysis, measuring for vertical deflection measured in nodes $C, F$ and $H$ of Truss $A$ and Truss $B$. The maximum value is obtained in Truss $\mathrm{B}$, along with a greater correlation between span and deflection. Regardless, in both trusses the value of L/d is smaller than the limits imposed by EN1993-1-1 (CEN, 2005).

Krichko, Kori; Valente, Isabel B. (2018)

Engineering History and Heritage, ISSN 1757-9430. 
Table 9 - Maximum vertical deflection in trusses of Room A and Room B

\begin{tabular}{|l|c|c|}
\cline { 2 - 3 } \multicolumn{1}{c|}{} & Trusses of Room A & Trusses of Room B \\
\hline Max deflection $(\mathbf{m})$ : joints $\boldsymbol{C}, \boldsymbol{F}, \boldsymbol{H}$ & -0.0014 & -0.0090 \\
\hline $\boldsymbol{L}(\mathbf{m})$ & 7.62 & 6.00 \\
\hline $\mathbf{L}$ /Max deflection $(\mathbf{m})$ & 544.9 & 666.7 \\
\hline
\end{tabular}

\section{CONCLUSIONS}

As a prominent player in the textile industry in Portugal during the late $19^{\text {th }}$ and the $20^{\text {th }}$ century, with cultural ties to the local community, Fábrica do Paleão should be maintained and preserved as an authentic example of industrial heritage. This study was performed to provide insight on the history and present structural condition of the structure to encourage future occupancy.

\section{Visual Inspection}

The visual inspection provided key parameters for further structural assessment. Through visual aids and the date of construction, the internal metallic structure was identified as cast iron columns and a light wrought iron roof truss. Other materials include the external and partition masonry walls typical of this period of industrial construction and the flooring and roofing materials.

Damage documentation and mapping reveal the effects of moisture throughout the structure due to a lack of maintenance. A large majority of the damages identified, including corrosion in the columns, vegetation in the slabs and spalling in the external masonry walls, are directly related to the presence of moisture due to a lack of regular maintenance since the closing of the factory.

\section{In situ Testing}

In situ testing focused on the metallic internal structure of the factory, identified as the main structural system. To gather site-specific parameters and assess the extent of the damages, two types of in situ tests were performed on the cast iron columns. By drilling small holes in the shaft of multiple columns, it was possible to measure the wall thickness of the hollow circular columns and perceive eccentricities.

Some level of corrosion was detected in each of the three columns tested for hardness, but similar results and comparison to known values indicate the columns align with ordinary to high strength cast iron. The results could also be correlated to the tensile strength of the columns, an important parameter for the safety assessment of the structure.

Krichko, Kori; Valente, Isabel B. (2018)

Fábrica do Paleão: Structural Assessment of Iron in Portugal's Industrial Heritage.

Paper submitted to Proceedings of the Institution of Civil Engineers -

Engineering History and Heritage, ISSN 1757-9430. 
To summarize the key results of the hardness test, a treated average Brinell hardness of 200.9 was obtained with a corresponding tensile strength of around $230 \mathrm{MPa}$ for the three cast iron columns tested. Hardness is a direct result of the test, with some statistical treatment of the results to account for the variability due to human error, equipment limitations and imperfections in the material. The tensile strength is strictly an estimated value based on the relationship between hardness and strength.

\section{Structural Analysis and Safety Assessment}

The repeated frame structure could be analyzed as a single two-dimensional frame for each of the two main industrial spaces. The model was constructed with all of the gathered parameters, assuming the behavior of the joints based on observed connections. To account for the unknown behavior of the joints in the roof truss, a sensitivity analysis was performed comparing an assumed "real" model with the two extreme scenarios, all fixed and all hinged joints, and adjusted accordingly.

Two load combinations were analyzed, accounting for the presence and absence of strong winds. Loads computed for trusses in Room A were much greater than loads applied to trusses in Room B due to the larger roof surface area supported by the first ones, with a longer span and greater distance between frames. The two models were run to determine axial forces and bending moments for each member, assessing their safety when subjected to combined axial and bending moments (Rondal et al, 2004). The analysis determined that some of the flat bar members were considered unsafe due to buckling behavior in strong winds.

To complete the safety assessment, the vertical deflection was computed for a third load combination. In all of the members, the vertical deflection was smaller than the limits imposed by EN1993-1-1 (CEN, 2005).

\section{Recommendations}

The main cause of structural damage observed is lack of maintenance in recent years, allowing moisture to penetrate the structure. It appears that the internal metallic structure has not been significantly impacted, however if the system continues to be exposed, adverse structural effects will appear. To avoid these effects, the entrance of water should be prevented. Effective immediate action would be to clear and repair the drainage system, however eventually a new roof will be required.

Krichko, Kori; Valente, Isabel B. (2018)

Fábrica do Paleão: Structural Assessment of Iron in Portugal's Industrial Heritage.

Paper submitted to Proceedings of the Institution of Civil Engineers -

Engineering History and Heritage, ISSN 1757-9430. 
Finding an alternative use for the large industrial plant is an effective solution to support regular maintenance and fund significant repairs to prevent further water damage.

\section{Future Work Proposed}

The analysis performed was focused on the internal metallic structure. In future assessments it would be advantageous to evaluate the condition and capacity of the masonry walls as well. If the factory is assigned a new use, the structure should be carefully assessed for required loads.

\section{Acknowledgements}

The authors would like to acknowledge the Belmiro de Azevedo Foundation for the permission to access and study the buildings and also the Municipality of Soure for the support given during the experimental work performed.

\section{REFERENCES}

Bates, W. (1991). Historical Structural Steelwork Handbook. London: The British Constructional Steelwork Association Limited.

Bussell, M. (1997). Appraisal of Exisiting Iron and Steel Structures. The Steel Construction Institute. Berkshire : The Steel Construction Institute.

Custodio, J. (1998). A Maquina a Vapor de Soure - um patrimonio industrial da Fundacao Belmiro de Azevedo. (A. G. Oliveira, M. Magalhaes, \& J. Custodio, Eds.) SONAE Imobilaria, S.A.

European Committee for Standardization. (2002). Eurocode 1: Actions on structures. Part 1-1: General actions - densities, self-weight, imposed loads for buildings. Brussels.

European Committee for Standardization. (2005a). Eurocode 1: Actions on structures. Part 1-4: Genral actions - Wind actions. Brussels.

European Committee for Standardization. (2005b). Eurocode 3: Design of Steel Structures. Part 1-1: General rules and rules for buildings. Brussels.

GSA. (1998a). Cast Iron: Characteristics, Uses and Problems. Outdoor Sculpture Manual - Center for Public Buildings .

GSA. (1998b). Wrought Iron: Characteristics, Uses and Problems. Historic Preservation Technical Documents.

Krichko, Kori; Valente, Isabel B. (2018)

Fábrica do Paleão: Structural Assessment of Iron in Portugal's Industrial Heritage.

Paper submitted to Proceedings of the Institution of Civil Engineers -

Engineering History and Heritage, ISSN 1757-9430. 
Krause, D. (1969). Gray Iron- A Unique Engineering Material. Iron Casting Research Institute, Philadelphia.

Atlas Foundry Company - AFC (2015). Mechanical Properties of Gray Iron - Hardness. Retrieved June 5, 2015 from Atlas Foundry Company: www.atlasfdry.com/grayiron-hardness.htm Verhoef, A. P. (Ed.). (1999). Problems and Possibilities - Cast Iron, Wrought Iron, Steel. International Congress on Urban Heritage and Building Maintenance. Delft: Office Faculty of Architecture Delft University of Technology.

Proceq SA. (n.d.). Metal Hardness Tester - Equotip Bambino 2. Retrieved June 1, 2015 from proceq: www.proceq.com/nondestructivetestequipment/metal-testing/hardness-testing/equotipbambino-2.html

Rondal, J., Rasmussen, K. J. (2004). On the strength of cast iron columns. Journal of Constructional Steel Research, Vol 60, Issue 9, pp. 1257-1270.

Krichko, Kori; Valente, Isabel B. (2018) 